\title{
Demonstration of LOTUS Multiphysics BEPU Analysis Framework for LB-LOCA Simulations
}

Hongbin Zhang, Ronaldo Szilard, Aaron Epiney, Rodolfo Vaghetto, Heng Ban, Cole Blakley

August 2018

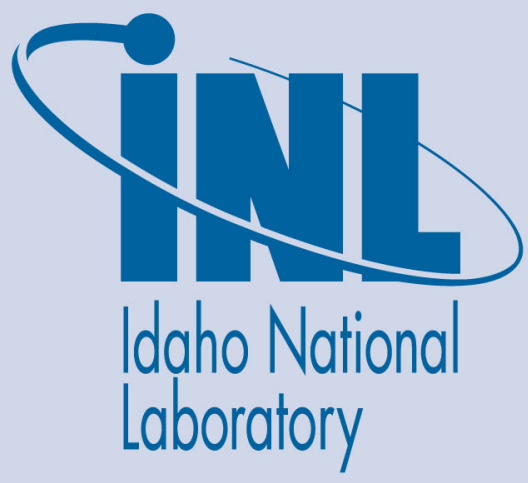

The INL is a U.S. Department of Energy National Laboratory operated by Battelle Energy Alliance 


\title{
Demonstration of LOTUS Multiphysics BEPU Analysis Framework for LB-LOCA Simulations
}

\author{
Hongbin Zhang, Ronaldo Szilard, Aaron Epiney, Rodolfo Vaghetto, Heng Ban, \\ Cole Blakley
}

\author{
August 2018 \\ Idaho National Laboratory \\ Idaho Falls, Idaho 83415 \\ http://www.inl.gov \\ Prepared for the \\ U.S. Department of Energy \\ Under DOE Idaho Operations Office \\ Contract DE-AC07-05ID14517
}




\title{
Demonstration of LOTUS Multiphysics BEPU Analysis Framework for LB- LOCA Simulations
}

\author{
Cole Blakely ${ }^{1}$, Hongbin Zhang ${ }^{2, *}$, Ronaldo Szilard ${ }^{2}$, Aaron Epiney ${ }^{2}$, Rodolfo Vaghetto ${ }^{3}$, \\ Heng Ban ${ }^{4}$ \\ ${ }^{1}$ Department of Mechanical and Aerospace Engineering, \\ Utah State University, Old Main Hill, Logan, UT 84322 \\ ${ }^{2}$ Idaho National Laboratory, 2525 Fremont Ave., Idaho Falls, ID 83415 \\ ${ }^{3}$ Department of Nuclear Engineering \\ Texas A\&M University, College Station, Texas 77843 \\ ${ }^{4}$ Department of Mechanical Engineering \& Materials Science \\ University of Pittsburgh, 3700 O'Hara Street, Pittsburgh, PA 15261
}

\begin{abstract}
The LOCA Toolkit for U.S. light water reactors (LOTUS) currently under development at Idaho National Labs (INL) is a plug and play, multiphysics environment to be used in support of system level plant transient analysis. New proposed rule changes in LOCA safety regulations (10 CFR $50.46 \mathrm{c})$ require the inclusion of cladding hydrogen content in the evaluation of equivalent cladding reacted (ECR) and peak cladding temperature (PCT). The potential for a future implementation of said rule change motivates the current development of a unique union of core design, system analysis, and fuel performance codes within a framework allowing for uncertainty quantification (UQ). A demonstration of LOTUS capabilities to address this potential need is performed with an integration of the core design code PHISICS, the fuel performance code FRAPCON, and the system analysis code RELAP5-3D. UQ is performed via Wilks' method to compute the one sided 95/95 confidence values of the aforementioned safety metrics. Results demonstrate the benefits of the Multiphysics Best Estimate Plus Uncertainty (MP-BEPU) methodology and provide useful visualization of the limiting cases.
\end{abstract}

KEYWORDS

LOTUS, Multiphysics Environment, Uncertainty Quantification, 10 CFR 56.46c, LB-LOCA

\begin{abstract}
ABREVIATIONS
\end{abstract}
BA Burnable Absorber

BEPU Best Estimate Plus Uncertainty

BOC Beginning of Cycle

CASL Consortium for Advanced Simulation of Light Water Reactors

CD-A Core Design-Automation

CD-O Core Design-Optimization

CFD Computational Fluid Dynamics

CRAM Chebyshev Rational Approximation Method

ECCS Emergency Core Coolant System

ECR Equivalent Cladding Reacted

ECRR Equivalent Cladding Reacted Ratio

\footnotetext{
*Corresponding author. Email address: Hongbin.Zhang@inl.gov.
} 


$\begin{array}{ll}\text { EOC } & \text { End of Cycle } \\ \text { FOM } & \text { Figures of Merit } \\ \text { FP } & \text { Fuel Performance } \\ \text { IFBA } & \text { Integral Fuel Burnable Absorber } \\ \text { INL } & \text { Idaho National Laboratory } \\ \text { INSTANT } & \text { Intelligent Nodal and Semi-structured Treatment for Advanced Neutron Transport } \\ \text { LB-LOCA } & \text { Large Break Loss Of Coolant Accident } \\ \text { LOCA } & \text { Loss Of Coolant Accident } \\ \text { LOTUS } & \text { LOCA Toolkit for U.S. Light Water Reactors } \\ \text { LWR } & \text { Light Water Reactor } \\ \text { MOOSE } & \text { Multiphysics Object-Oriented Simulation Environment } \\ \text { MP-BEPU } & \text { Multiphysics Best Estimate Plus Uncertainty } \\ \text { MRTAU } & \text { Multi-Reactor Transmutation Analysis Utility } \\ \text { NEAMS } & \text { Nuclear Energy Advanced Modeling and Simulation } \\ \text { NRC } & \text { Nuclear Regulatory Commission } \\ \text { PCT } & \text { Peak Cladding Temperature } \\ \text { PCTR } & \text { Peak Cladding Temperature Ratio } \\ \text { PDF } & \text { Probability Density Function } \\ \text { PHISICS } & \text { Parallel and Highly Innovative Simulation for the INL Code System } \\ \text { PWR } & \text { Pressurized Water Reactor } \\ \text { PPM } & \text { Parts Per Million } \\ \text { UQ } & \text { Uncertainty Quantification } \\ \text { VERA } & \text { Virtual Environment for Reactor Analysis } \\ \text { RELAP } & \text { Reactor Excursion and Leak Analysis Program } \\ \text { SA } & \text { Systems Analysis } \\ \text { RA } & \text { Risk Assessment } \\ \text { RIA } & \text { Reactivity Insertion Accidents } \\ \text { WPPM } & \text { Weighted Parts Per Million } \\ & \end{array}$

\section{INTRODUCTION}

Mathematical modeling of light water reactors (LWR) requires capturing the effects of multiple, interconnected physical phenomena. Lately, the needed computational models for LWR simulations are being placed in computational environments. The word environment is amorphous (Sloan et al., 2013), however in this work it is taken to define a computational space in which programs are treated as modules by which large amounts of data can be created, exchanged, and processed.

A number of multiphysics environments are being developed within the nuclear community by a variety of different groups. Instances include MOOSE at Idaho National Laboratory (INL) (Gaston et al., 2009), VERA by the Consortium of Advanced Simulation of Light Water Reactors (CASL) (https://www.casl.gov/, 2018), and the Nuclear Energy Advanced Modeling and Simulation (NEAMS)'s Workbench (Swiler et al., 2017). It is worth noting that many others have created multiphysics couplings between codes which may be considered environments. However for the sake of brevity, only relatively recent multiphysics environments intended to be platforms for a plethora of future studies in nuclear energy are listed here.

Current work at INL includes the building of a new multiphysics environment known as the LOCA Toolkit for U.S. Light Water Reactors (LOTUS). The LOTUS environment is unique in the use and size of HDF5 databases (https://www.hdfgroup.org/solutions/hdf5/, 2018), allowing for a flexible plug and play environment. The focus of this work is to use LOTUS to build an integration of codes capable of 
enhancing system level plant transient analysis during large break loss of coolant accident (LB-LOCA) conditions.

As a demonstration, LOTUS is used to evaluate new LOCA safety metrics under U.S. Nuclear Regulatory Commission (NRC)'s proposed 10 CFR 50.46c new rulemaking (U.S. Nuclear Regulatory Commission, 2014). LOTUS would be adept at analyzing these new metrics as they require integrated core design, fuel performance, and systems analysis calculations. Pending approval by the U.S. NRC, some of the potential new rules of $10 \mathrm{CFR} 50.46 \mathrm{c}$ would require taking pre-transient cladding hydrogen content into account in the evaluation of peak cladding temperature (PCT) and the equivalent cladding reacted (ECR). The PCT and ECR limits as functions of pre-transient cladding hydrogen content in weighted parts per million (wppm) are shown in Figure 1.
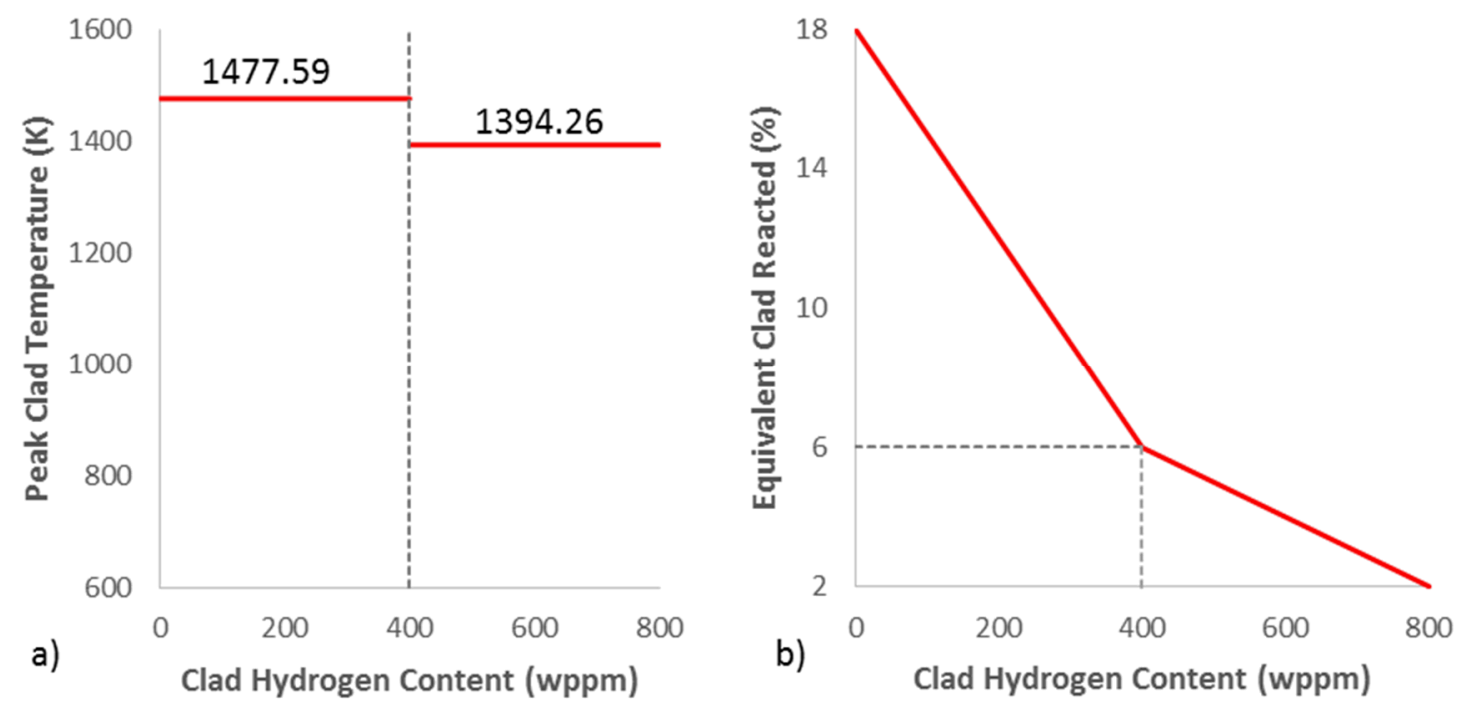

Figure 1: a) PCT and b) ECR Limit as Functions of Cladding Hydrogen Content.

ECR and PCT can be calculated within the well-established system analysis code RELAP5-3D. However, cladding hydrogen content can only be obtained from fuel performance simulations of the fuel depletion preceding the LOCA event. This work seeks to resolve this issue by using LOTUS to integrate RELAP53D (The RELAP5-3D Code Development Team, 2012) with the fuel performance code FRAPCON (http://frapcon.labworks.org/, 2018).

The integration of system analysis codes with fuel performance codes has been performed in the past. A foundational work has been performed for the generic, semi-implicit coupling of RELAP5-3D with COBRA, CONTAIN, as well as computational fluid dynamic CFD codes (Weaver et al., 2002).

Integration of a past version of RELAP (RELAP4) with FRAPCON has also been performed (Marra Neto et al., 1989).

Notable thermal hydraulic coupling with FRAPCON includes a coupling between a customized version of FRAPCON and the thermal hydraulic code TRACE for a quasi-steady state depletion case (Porter et al., 2015). FRAPTRAN has also been coupled with the thermal hydraulic code COBRA-TF and the neutronics code TORT-TD (Magedanz et al., 2015). A comparison of a FRAPCON/COBRA-TF/TORTTD coupling to a COBRA-TF/TORT-TD coupling (with COBRA-TF handling the fuel performance) was also conducted (Yilmaz et al., 2017). Recent work at INL has focused on the modeling of reactivity 
insertion accidents (RIA) using a coupling of RELAP5-3D with the new fuel performance code BISON (Folsom et al., 2016).

LOTUS also supplies FRAPCON and RELAP5-3D with power profiles from the neutronics code PHISICS as previously outlined in past work (Epiney et al., 2017). The coupling methodology of PHISICS to RELAP5-3D is well documented (Strydom et al., 2017).

Noteworthy multiphysics studies involving RELAP5-3D with specialized neutronics calculations include a coupling with the SIMULATE-3K code (Judd et al., 2009). Fuel performance codes have also been coupled with a variety of neutronics codes in the past. Examples include a coupling of FRAPCON with SCALE (Bratton et al., 2015), an integration of FRAPCON with the CASMO/SIMULATE package (Deng et al., 2018), and BISON with DeCART (Hales et al., 2015), SERPENT (Wu et al., 2015), and RATTLESNAKE (Gleicher et al., 2014) .

In comparison to the aforementioned multiphysics studies, this work is unique in two aspects. Firstly, it focuses on the evaluation of ECR and PCT with respect to limits based on pre-transient cladding hydrogen content. Secondly it performs uncertainty quantification (UQ) on the outputs of interest. In any mathematical model intended to be reflective of reality, all calculations and inputs have uncertainties. Due to the vast number of inputs and calculations within a multiphysics environment, it is particularly important to quantify the cumulative effects of uncertainties. UQ is essential in complying with the industry standard of best estimate plus uncertainty (BEPU) methodology. BEPU ensures that decisions makers are always privy to the corresponding level of confidence for all calculated values of concern.

The incorporation of BEPU methods within a multiphysics environment is known as multiphysics best estimate plus uncertainty (MP-BEPU) methodology. MP-BEPU is superior to standard BEPU in that more inputs and calculation biases may be concurrently perturbed. Furthermore, MP-BEPU may also allow for less conservative estimates of safety metrics. These improved estimates have the potential to decrease plant safety margins, thereby allowing higher operation power and/or greater flexibility during power maneuvers.

Within this work, only FRAPCON and RELAP5-3D input decks are subject to perturbations. The MPBEPU methodology implemented in this work is focused on fuel performance and system analysis. Thus while the PHISICS code is given proper attention, the primary emphasis is on the FRAPCON and RELAP5-3D codes. Future work will fully incorporate core design within the MP-BEPU methodology.

The primary objectives of this work are to describe the unique benefits of the LOTUS framework, and provide UQ of PCT and ECR measures using Wilks' method for a large break loss of coolant accident. The figures of merit (FOM) are to be evaluated for a LB-LOCA for an equilibrium cycle of a generic four-loop pressurized water reactor (PWR) at the beginning of cycle (BOC), and end of cycle (EOC) as well as 100 days, 200 days, 300 days, 400 days, and 500 days into the cycle. From the sample, the limiting case with respect to each FOM is presented and analyzed.

\section{LOTUS DESCRIPTION}

As shown in Figure 2, LOTUS will provide an environment for the integration of multiple codes within the disciplines of Core Design Automation (CD-A), Fuel Performance (FP), Systems Analysis (SA), and Core Design Optimization (CD-O). LOTUS will also include Uncertainty Quantification (UQ), Sensitivity Analysis (SA), and Risk Assessment (RA). 


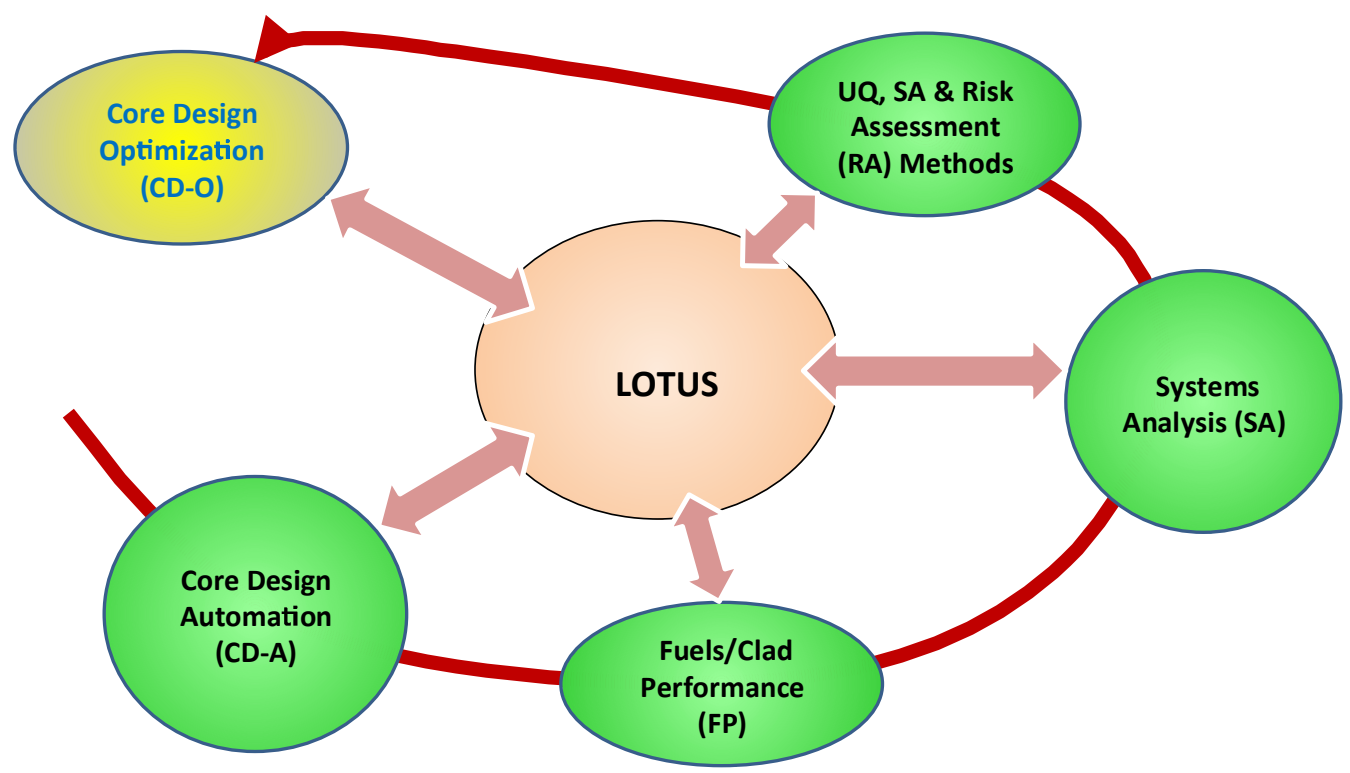

Figure 2. Conceptual Schematic of LOTUS Capabilities.

The integration presented in this work demonstrates CD-A using the PHISCS code, fuel performance using the FRAPCON code, and system analysis using the RELAP5-3D code in conjunction with UQ software, which is only a portion of eventual capabilities. As Figure 2 suggests, LOTUS will eventually entail additional codes. LOTUS stores all data within HDF5 databases (see section 3). This method of storage allows the results of past cases to be accessed by later works, thereby avoiding redundancies in future code integrations.

\subsection{Code Description}

This section contains descriptions of PHISCIS, FRAPCON, and RELAP5-3D as well as a section detailing code discrepancies.

\subsubsection{PHISICS}

The PHISICS (Parallel and Highly Innovative Simulation for the INL Code System) code toolkit is being developed at the Idaho National Laboratory (Rabiti et al., 2016). This package is intended to provide a modern analysis tool for reactor physics investigations. It is designed to maximize the accuracy for a given availability of computational resources and to give state-of-the-art tools to the nuclear engineer. PHISICS output files contain the core power distribution for three dimensional core geometries at a variety of states.

The software is completely modular in order to simplify independent development of modules and maintenance by different teams. The different modules currently available in the PHISICS package are the core solver (INSTANT), a depletion module (MRTAU), a time-dependent solver (TimeIntegrator), a cross section interpolation and manipulation framework (MIXER), a criticality search module (CRITICALITY) and a fuel management and shuffling component (SHUFFLE).

The transport core solver INSTANT (Intelligent Nodal and Semi-structured Treatment for Advanced Neutron Transport) (Wang et al., 2011) is the key kernel of the PHISICS framework. INSTANT is parallelized and is designed to take full advantage of medium to large clusters (10 to 1000 processors). It 
is based on the second-order formulation of the transport equation discretized in angle by spherical harmonics while in space it uses orthonormal polynomials of an arbitrary order. In addition to steady-state solutions, INSTANT is able to solve time-dependent problems. For that, a scheme based on a secondorder backward Euler scheme with explicit delayed neutron treatment has been implemented as a new module for the PHISICS suite (Epiney et al., 2012, Rabiti et al., 2016).

MRTAU (Multi-Reactor Transmutation Analysis Utility) (Alfonsi et al., 2012) is a generic depletion code developed at INL. In addition to core depletion, the code can be utilized for stand-alone decay heat calculations. It tracks the time evolution of the isotopic concentration of a given material accounting for nuclear reactions occurring in the presence of neutron flux and also due to natural decay (Bateman equation). The code uses a Taylor series expansion-based algorithm at arbitrary order and the Chebyshev Rational Approximation Method (CRAM) for computation of the exponential matrix.

The MIXER module (Epiney et al., 2012) does all the cross-section handling for the different kernels. MIXER can handle macroscopic, microscopic, and "mixed" cross sections. MIXER can read different cross-section library formats. Among them is an original simple XML-based format, but also AMPX, ISOTXS, and ECCO library formats that allow cross-section libraries to be prepared with SCALE, ERANOS, or MC2.

\subsubsection{FRAPCON}

FRAPCON (http://frapcon.labworks.org/, 2018) is a fuel performance code developed by Pacific Northwest National Laboratories over the course of forty years. FRAPCON is a mature technology with extensive experimental validation for quasi-steady state depletion cases. The code is $1 \frac{1}{2}$ dimensional, meaning the equations are solved in an axisymmetric fashion, with only the radial direction fully solved. The code includes axial effects such as axial power peaking factors, and a single channel enthalpy rise model for the coolant. Furthermore, fission gas release and plenum pressure are computed based off of the cumulative effects of all axial locations.

FRAPCON simulations are very numerically stable and fast for PWR problems, with run times of roughly two seconds per case. FRAPCON often relies upon empirical relations in areas where more recent codes use more mechanistic models. While this limits the robustness of the code for new fuel and reactor designs, it is advantageous in performance and accuracy for PWR cases involving traditional materials.

\subsubsection{RELAP5-3D}

RELAP5-3D (The RELAP5-3D Code Development Team, 2012) is a simulation tool that allows users to model the behavior of the reactor coolant system and the core for various operational transients and postulated accidents that might occur in a nuclear reactor. RELAP5-3D (Reactor Excursion and Leak Analysis Program) can be used for reactor safety analysis, reactor design, simulator training of operators, and as an educational tool by universities. RELAP5-3D is developed and maintained at INL. It is able to model the behavior of the plant system (heat exchangers, steam generators, pumps, valves, etc.) and the thermal-hydraulics of the reactor core. The code was specifically designed for simulations of light water reactor (LWR) transients such as loss of coolant (LOCA), anticipated transients without scram, and operational transients such as loss of feed-water, etc.

RELAP5-3D input decks allow considerable user control. The structure of the code permits users to assign values to a vast number of material and performance parameters, as well as bias many individual 
thermal hydraulic calculations (i.e. the estimation of heat transfer coefficients). This flexibility allows for extensive input perturbations as shown in the list of perturbed inputs of this work (see section 3.2).

\subsection{Model Inconsistencies}

Differences between PHISICS, FRAPCON, and RELAP5-3D fall into one of three categories, the domain of the code, phenomena modeled, and numerical discretization.

\subsubsection{Code Domain}

In terms of domain, PHISICS models a full reactor core while FRAPCON models individual fuel rods within an idealized single coolant subchannel. RELAP5-3D models a set of heat structures representing the full core, as well as the entire primary and secondary coolant loops and the Emergency Core Coolant System (ECCS). Essentially PHISICS and FRAPCON model a small subspace of the full RELAP5-3D domain. The largest discrepancies stemming from these domain differences are in the form of boundary conditions.

FRAPCON and PHISICS specify a core inlet temperature, outlet pressure, and mass flow rate or flux, all of which are not boundary conditions within RELAP5-3D as there are no domain boundaries at the core inlet and outlet. In the interests of minimizing the discrepancy to the extent possible, the PHISICS values and FRAPCON nominal values of mass flux and outlet pressure were selected based off the results of the nominal case of RELAP5-3D. Also the nominal FRAPCON inlet nominal temperature was selected based on the supplied input to PHISICS.

\subsubsection{Phenomena Modeled}

The phenomenological differences between PHISICS, FRAPCON, and RELAP5-3D are vast. FRAPCON and RELAP5-3D have evolved separately over forty years to solve very different types of problems, while PHISICS is a modern code relying on more recently developed methods. As a result there are large variations in the specific phenomena modeled as well as in the sophistication and numerical accuracy of the individual models involved.

For instance, RELAP5-3D has extensive empirical relations for coolant heat transfer coefficients while FRAPCON only utilizes two relations (one for forced film convection and the other for nucleate boiling). Conversely FRAPCON contains dynamic gap conductance models which take into account material deformation, fission gas release, pellet cladding mechanical interaction and irradiative effects, while the dynamic gap conductance model of RELAP5-3D uses simplified gap deformation models in conjunction with the ideal gas law (constant gas composition assumed).

The elimination of the majority of these phenomenological discrepancies is either not reasonable, beyond the scope of this work, and/or of little benefit. In most cases, extensive validation has established that the simplifications within each code are appropriate for specific problems they encounter. The primary difference of concern resides in the heat equations of FRAPCON and steady state simulations of RELAP5-3D. These issues will be resolved in future work centered on calibrating RELAP5-3D to FRAPCON based on stored internal energy. Within the context of this work, PHISICS and FRAPCON may be thought of as initialization modules within the RELAP5-3D framework.

PHISICS provides power histories to FRAPCON and the core power shapes at the time of LB-LOCA to RELAP5-3D. FRAPCON solves a quasi-steady state depletion problem, which RELAP5-3D is not equipped to model. Fuel performance data from FRAPCON is then supplied to RELAP5-3D as means to potentially enhance the fidelity of the RELAP5-3D. RELAP5-3D then executes a LB-LOCA simulation, 
which FRAPCON is incapable of performing. The integration of these codes within LOTUS, while not an all-encompassing model of true reactor physics, is an improvement over more compartmentalized approaches.

\subsubsection{Discretization}

For steady state simulations of the fuel rods, both the FRAPCON and RELAP5-3D codes use finite difference approximations which solve the heat conduction equation in the radial direction alone, but allow for axial variation in linear heat rates. This is referred to as $1 \frac{1}{2} \mathrm{D}$ in FRAPCON documentation. While there are phenomenological differences in the computation of thermal conductivity, the numerical methods themselves do not contain significant discrepancies.

Within this work, the number of radial and axial nodes differs between code input files. When solving the heat equation, FRAPCON has 17 radial elements in the fuel and 5 in the cladding while RELAP5-3D has only 5 in the fuel and 2 in the cladding. Note that FRAPCON uses the analytical solution from the thick wall approximation when computing stresses and 45 radial nodes in fission gas release calculations. However in the interests of comparing similar models, only the discretization used for solving the heat equations in FRAPCON is compared here. The PHISICS and FRAPCON input files have 15 axial elements within the fuel rod while RELAP5-3D uses 6 axial elements in the interests of maintaining reasonable run times. Thus within this work, FRAPCON and PHISICS use greater spatial discretization as compared to the heat structures of RELAP5-3D. Once again it is stressed that FRAPCON and PHISCS can be seen as modules used for the initialization of the core within the RELAP5-3D structure. Thus numerical approximations within RELAP5-3D do not affect FRAPCON or PHISICS, and potential improvements in numerical estimates within PHISICS and FRAPCON serve only to enhance traditional RELAP5-3D studies.

\section{LOTUS STRUCTURE}

LOTUS retrieves all values of interest from output files and stores them in a more compact manner. The data is also easily accessible for other codes. Provided that the needed data was calculated and stored, any arbitrary codes can be added into the LOTUS structure in an ad-hoc manner and access previously generated data. This flexibility in storage allows for a plug and play environment. The data flow structure of this work is shown in Figure 3.

The colors of the arrows in Figure 3 correspond to specific groups of data within the HDF5 database. The yellow color refers to power shapes generated by PHISICS which are stored within the HDF5 database and later retrieved by FRAPCON and RELAP5-3D. The green color denotes fuel performance data calculated by FRAPCON, stored in the database, and later used by RELAP5-3D and UQ and SA post processors. Lastly the green color indicates PCT and ECR data generated by RELAP5-3D, stored in the database, and then supplied to UQ and SA post processors.

For this specific work which includes a nominal case and 93 perturbed cases at each selected cycle exposure point (see section 4.4), the entire HDF5 database uses $4.4 \mathrm{G}$ as opposed to $1.2 \mathrm{~TB}$ if all PHISICS, FRAPCON, and RELAP5-3D files were to be stored. This compression in data will be essential in later works involving Monte Carlo analysis with sample sizes on the order of thousands.

It is worth noting that the codes within this work are integrated, not coupled. While some sources would consider the data flow shown in Figure 3 to be an one-way or even loose coupling, within this work the term coupling indicates feedback between codes. Plans for future work include a tight coupling of transient fuel performance and systems analysis codes for increased fidelity in LOCA simulations. 


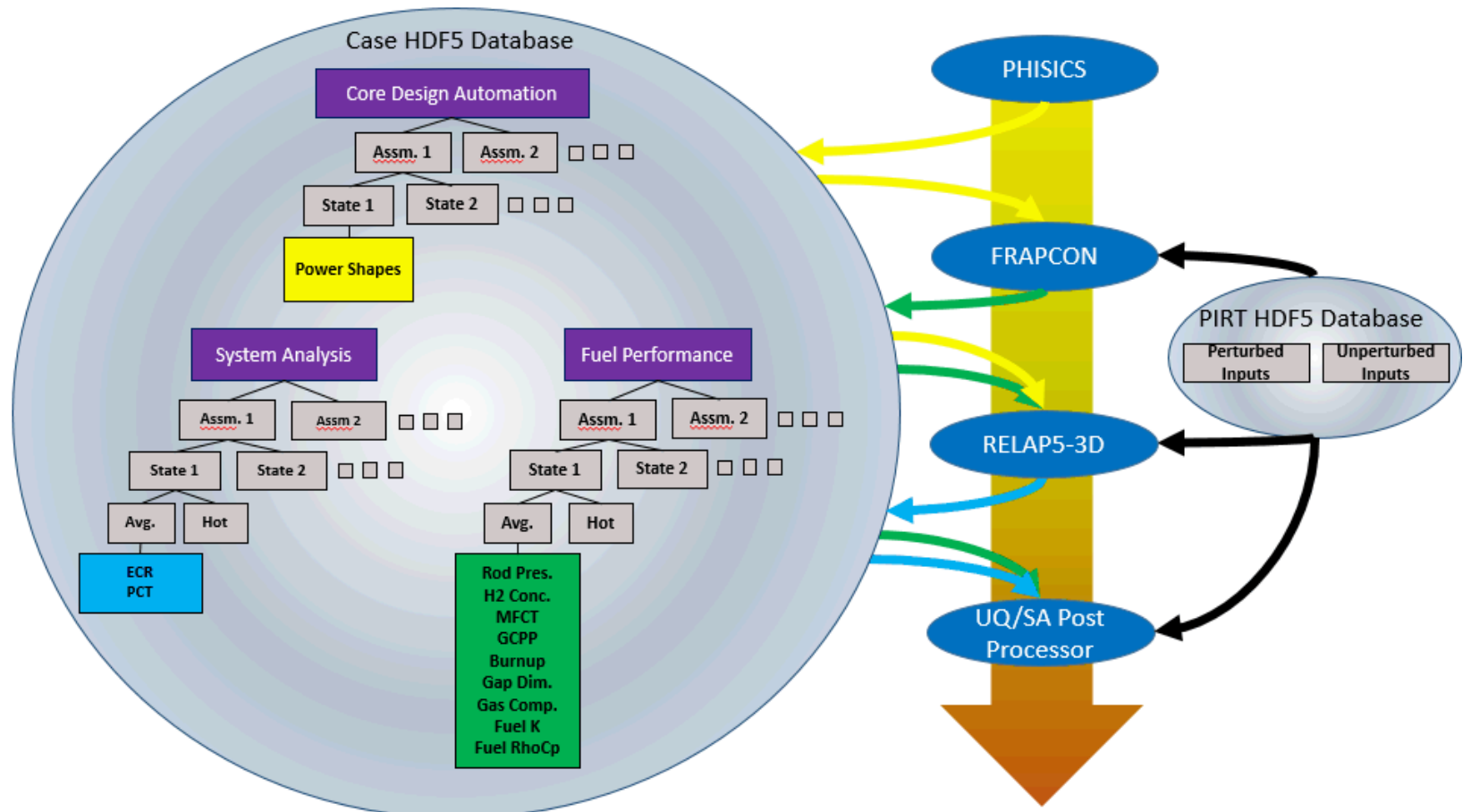

Figure 3: LOTUS Data Flow Structure for a Single Instance of Monte Carlo Sampling. Colors of Arrows Connecting Case HDF5 Database to Codes Correspond to HDF5 Database Group.

Critical to MP-BEPU is consistent uncertainty propagation. The output of any code has a level of uncertainty. In cases where the frequency of code executions is limited by hardware constraints, more computationally expensive codes are executed a limited number of times. The resultant sample size is then used to create an estimated probability density function (PDF) for outputs of interest. A large sample size is then generated from these PDFs, which can then be used by less expensive codes.

Fortunately due to the mere 93 runs required by Wilks' method (see section 4.4) and the large computational resources available at INL, a more preferable direct connection method is possible. In this method, the data is passed directly between codes for each instance of the sample. Essentially, the combination of the codes is treated by the UQ routines as a single code. This direct connection method is preferable as it eliminates the aforementioned multiple samplings and is more numerically accurate as PDF estimation is not required.

As shown in Figure 3, no perturbed values are passed to PHISICS input files. The output data from PHISICS, which is essentially the core power distribution at several states of interest, is treated as a constant. A sample of perturbed PHISICS output files was not generated due to run time concerns. It is again emphasized that this work serves as a foundation, by which later work will include MP-BEPU analysis with fully incorporated core design codes.

\subsection{PHISICS Data Exchange}

PHISICS output data contains core power shapes for each assembly at a large variety of states. The data set of each state contains coordinates for finite elements with their corresponding portion of the total core power. From this data, the core power shapes for 18 states of interest within an 18 month equilibrium fuel cycle are extracted. LOTUS also crops the data to the domain of the fuel rods. The axial power profile is 
then assigned to a group within an HDF5 database. The name of this group is based upon user supplied text files which relate Cartesian coordinates in the core to assembly name notation within PHISICS and RELAP5-3D. In the LOTUS build used in this work, no data is supplied to PHISICS from HDF5 databases.

\subsection{FRAPCON Data Exchange}

FRAPCON obtains axial power peaking profiles and axial averaged heat rates from LOTUS. The axial averaged power peaking profiles were obtained by first extrapolating the elemental averaged power portions of PHSICS to the normalized, nodal linear heat rates required by FRAPCON. Safeguards are put in place to assure that any negative values from the extrapolation are replaced with zero (Eq. 1). The nodal values are then normalized by the rod average value as shown in Eq. 2,

$$
\begin{gathered}
q_{i}^{\prime N}=\max \left(w_{i-1} \frac{\Delta Q_{i-1} / Q}{L_{i-1}}+w_{i} \frac{\Delta Q_{i} / Q}{L_{i}}, 0\right) Q \\
\widetilde{q_{i}^{\prime N}}=\frac{q_{i}^{\prime N}}{1 / 2 L_{\text {rod }} \sum_{j}^{n E l e m}\left(q_{j-1}^{\prime N}+q_{j}^{\prime N}\right) L_{j}}
\end{gathered}
$$

where index $i$ corresponds to axial locations within individual rods, $\Delta Q_{i} / Q$ is the ratio of the power generated within an element $\left(\Delta Q_{i-1}\right)$ to the total core power $(Q), w_{i}$ represents the weightings used for extrapolation, $L_{i}$ and $L_{\text {rod }}$ are elemental and total rod lengths respectively, $q_{i}^{\prime N}$ is the nodal linear heat rate, and $\widetilde{q_{l} N}$ is the rod normalized nodal linear heat rate or rod power peaking profile.

The axial averaged heat rate is calculated according to Eq. 3 for the highest power or hot rod in an assembly. Eq. 4 calculates the heat rate for a representation of the average of the remaining rods in the assembly. Since the PHISICS code only calculates the assembly homogenized powers and it does not provide pin powers, the hot and average rod relations were defined based on the assumption that the hot rod produces 3\% more power than the average rod. The hot rod power increase of $3 \%$ was selected arbitrarily for demonstration purposes and highlights the need to bring in pin resolved power distributions in future work.

$$
\begin{aligned}
& \overline{q_{\text {hot }}^{\prime}}=\left(\sum_{i}^{\text {nElem }} \Delta Q_{i} / Q\right)\left(\frac{1.03}{263+1.03}\right) \frac{Q}{L_{\text {rod }}} \\
& \overline{{q_{\text {avg }}^{\prime}}^{\text {a }}}=\left(\sum_{i}^{\text {nElem }} \Delta Q_{i} / Q\right)\left(\frac{1}{263+1.03}\right) \frac{Q}{L_{\text {rod }}}
\end{aligned}
$$

where $\overline{q_{\text {hot }}^{\prime}}$ and $\overline{q_{\text {avg }}^{\prime}}$ are the axial averaged heat rates for hot and average rods respectively. $\overline{q^{\prime}}$ and $\widetilde{q_{l}^{\prime N}}$ are then supplied to FRAPCON for consecutive sets of states, which form power history. The composition of the power history is dependent on the time of the LB-LOCA and the shuffling scheme. For instance, a twice burned assembly subject to LB-LOCA at 300 days, will be supplied the full power 
histories for the previous two location of the assembly, as well as the first 300 days of the current location.

LOTUS does not assume that the hot rod location is consistent between fuel cycles. For this reason, the heat rates of the average rods are supplied to the power histories of hot rods for the previous cycles of once and twice burned assemblies, after which the $3 \%$ power increase is applied to the current cycle.

LOTUS also transfers the appropriate perturbed inputs (see Table IV) to each FRAPCON inputs file. The data transferred from FRAPCON to the HDF5 databases is shown in Table I. Note that not all data stored is used by RELAP5-3D. Many of the values such as stored internal energy and heat flux are stored in anticipation for later code integrations within LOTUS.

Table I. Stored Data from Single FRAPCON Case

\begin{tabular}{|l|c|}
\hline Name of Data Stored & Description of Data \\
\hline Axial Mesh (Nodal Locations) & Array of Floats (nAxial+1) \\
\hline Axially Averaged Burnup & Single Float \\
\hline Burnup & Array of Floats (nAxial) \\
\hline Fuel Centerline Temperature & Single Float \\
\hline Maximum Centerline Temperature & Array of Floats (nAxial) \\
\hline Gap Conductance & Single Float \\
\hline Gap Conductance at Peak Power & Array of Floats (nSpecies) \\
\hline Gas Compositions & Array of Floats (nAxial) \\
\hline Hydrogen Concentrations & Array of Floats (nAxial) \\
\hline Heat Flux & Array of Floats (nAxial) \\
\hline Inner Clad Displacement & Array of Floats (nAxial) \\
\hline Outer Clad Displacement & Array of Floats (nAxial) \\
\hline Outer Fuel Displacement & Single Float \\
\hline Outer Clad Diameter & Single Float \\
\hline Oxide Layer Thickness & Single Float \\
\hline Rod Internal Pressure & Array of Floats (nAxial) \\
\hline Stored Rod Internal Energy & Single Float \\
\hline Clad Thickness & Single Float \\
\hline Gap Thickness & \\
\hline
\end{tabular}

\subsection{RELAP5-3D Data Exchange}

RELAP5-3D receives power profiles from the data stored from PHISICS. The PHISCIS and RELAP53D core heat structure meshes were selected such that each of the six RELAP5-3D axial elements is an aggregate of multiple PHISICS elements. Thus no interpolation is needed, only a direct summation. The RELAP5-3D input deck contains two heat structures for each assembly, one representing 263 average fuel rods and the other a single hot rod. Both the average and hot heat structures require the portion of the power deposited within the fuel as well as the direct moderator heating portion. The power data supplied to RELAP5-3D are shown in Eqs. 5-8,

$$
\left(\Delta Q_{j} / Q\right)_{R E L A P}^{H o t, F u e l}=\left(\sum_{i \in j}\left(\Delta Q_{i} / Q\right)_{P H I S I C S}\right)\left(\frac{1.03}{263+1.03}\right)\left(1-F^{D M H}\right)
$$




$$
\begin{gathered}
\left(\Delta Q_{j} / Q\right)_{R E L A P}^{H o t, D M H}=\left(\sum_{i \in j}\left(\Delta Q_{i} / Q\right)_{P H I S I C S}\right)\left(\frac{1.03}{263+1.03}\right) F^{D M H} \\
\left(\Delta Q_{j} / Q\right)_{R E L A P}^{A v g, F u e l}=\left(\sum_{i \in j}\left(\Delta Q_{i} / Q\right)_{P H I S I C S}\right)\left(\frac{263}{263+1.03}\right)\left(1-F^{D M H}\right) \\
\left(\Delta Q_{j} / Q\right)_{R E L A P}^{A v g, D M H}=\left(\sum_{i \in j}\left(\Delta Q_{i} / Q\right)_{P H I S I C S}\right)\left(\frac{263}{263+1.03}\right) F_{D M H}
\end{gathered}
$$

Where $F^{D M H}$ is the direct moderator heating fraction, subscripts RELAP5-3D and PHSICS indicate the code to which the data corresponds, superscripts Avg and Hot indicate the type of RELAP5-3D heat structure, superscripts Fuel and $D M H$ indicate fuel power deposition and direct moderator heating respectively, and $i \in j$ indicates the set of PHISICS indices $i$ which reside in a specific RELAP5-3D index $j$. Table II contains the fuel performance data transferred for each assembly heat structure (both hot and average).

Table II. Fuel Performance for each Assembly Heat Structure within RELAP5-3D

\begin{tabular}{|l|c|}
\hline Name of Data Stored & Description of Data \\
\hline Rod Internal Pressure & Single Float \\
\hline Fuel Displacements & Array of Floats (nAxial) \\
\hline Inner Cladding Displacements & Array of Floats (nAxial) \\
\hline Initial Fuel Radius & Single Float \\
\hline Initial Inner Cladding Radius & Single Float \\
\hline Initial Outer Cladding Radius & Single Float \\
\hline Fuel Thermal Conductivity & Temperature Dependent Table \\
\hline Fuel Volumetric Thermal Capacity & Temperature Dependent Table \\
\hline Gas Composition & Species Dependent Table \\
\hline
\end{tabular}

The temperature dependent tables for fuel thermal conductivity and volumetric heat capacity vary among heat structures based upon burnup. The tables are generated by first obtaining the axially averaged burnup of each heat structure. These burnup values and a set or expected fuel temperatures are then supplied to Uranium Dioxide material modules from FRAPCON, thereby generating separate temperature dependent material properties for each heat structure. The fuel volumetric heat capacities also conserve mass by altering fuel density in inverse proportion to volumetric changes. The incorporation of these tables to create rudimentary burnup dependent fuel properties is an improvement in accuracy over traditional RELAP5-3D input decks.

The gas composition tables contain all present species and their corresponding mole fraction. LOTUS also transfers the perturbed inputs specific to RELAP5-3D (see Table IV.). The data transferred from RELAP5-3D to HDF5 databases are the maximum PCT and ECR encountered during the LB-LOCA for each assembly. 


\section{MP-BEPU ANALYSIS WITH LOTUS}

In the section, LB-LOCA analyses of a generic four-loop PWR is performed using multiphysics best estimate plus uncertainty (MP-BEPU) methodology within the LOTUS framework.

\subsection{Problem Description}

The problem of interest is a four-loop PWR with $3853 \mathrm{MW}$ rated thermal power. The number of fuel assemblies is 193 with $17 \times 17$ fuel rod design with 264 fuel rods and 25 non-fuel locations. The active core height is $4.2672 \mathrm{~m}$ (14 ft.).

\subsubsection{Core Design Automation}

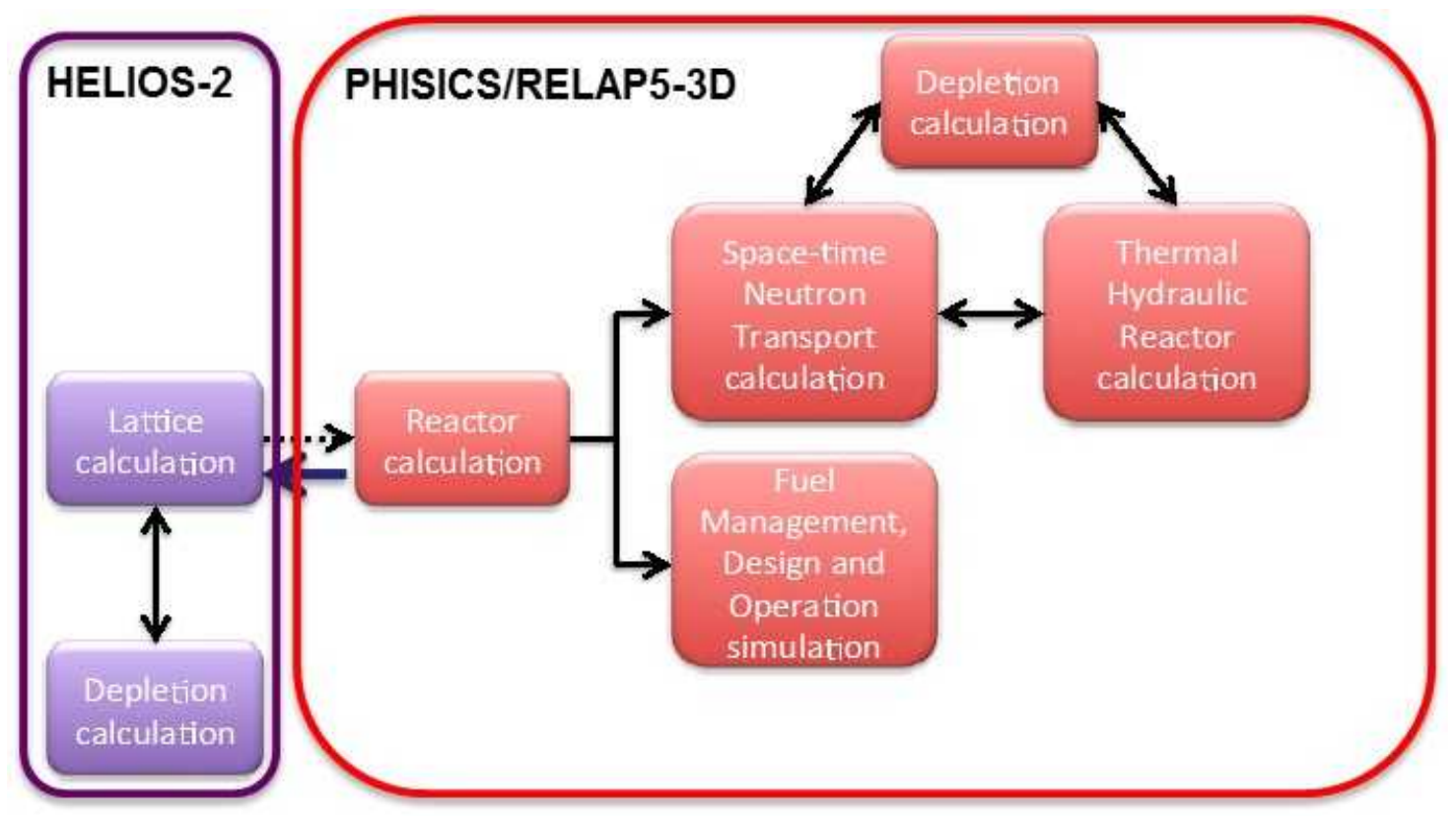

Figure 4. LOTUS Demonstration: Core Simulation Strategy.

The core simulation strategy employed to generate the data needed by the subsequent LOCA analysis is schematically shown in Figure 4. The first step of the strategy is to generate homogenized neutron cross sections. The lattice code HELIOS-2 (Wemple et al., 2008) is used to compute the cross sections for different geometrical conditions and different reactor states in the core. In this manner, a cross section library can be generated that captures effects like control rods, burnable poisons, etc. as well as different fuel temperatures, moderator densities, boron concentrations and burn-up levels. The PHISICS reactor physics package coupled to the thermal-hydraulic system code RELAP5-3D is used in a second step, in order to compute 3D assembly power distributions, burn-ups, etc. needed as initial conditions for the subsequent LOCA analysis. Depending on the available data base to initiate the calculation, (core and fuel geometry description, burn-up maps, reloading pattern, power distributions, etc.), the PHISICS package can, in addition to solve the 3D core, also burn the core to the desired burn-up level, shuffle and reload the core and search for critical control rod positions or boron concentrations. 
In this work, the LB-LOCA accident scenario is initiated from equilibrium cycle conditions to assess the compliance of the existing power plants to the proposed rule. From a loading point of view, the equilibrium cycle can be considered as the cycle from which the fuel reload pattern is almost constant (i.e. same composition and spatial loading of the fuel batches). In this work an equilibrium cycle is reached by following several operational cycles to achieve high burn-up, low radial power peaking and flat axial power profiles, i.e. somewhat realistic core conditions that represent a current PWR core. The loading pattern for the equilibrium cycle is shown in Figure 5. The numeric numbers on the loading map indicate the number of the Integral Fuel Burnable Absorber (IFBA) rods which are normal fuel rods that have a boron absorber coating sprayed on the cladding in the fresh fuel assemblies. The two enrichments found in order to reach, at the equilibrium, a cycle length of 18 months are $4.2 \%$ and $4.6 \%$. The fuel rods contain a low enriched zone at the top and bottom. The $\mathrm{k}_{\mathrm{eff}}$ at BOC has been found to be 1.10462 and the cycle ends when the $\mathrm{k}_{\text {eff }}$ falls below 1.0. Assuming a realistic boron worth of $\sim 10 \mathrm{pcm} / \mathrm{ppm}$, the maximum boron concentration in the core at BOC is expected be $\sim 1000 \mathrm{ppm}$ which is in the range of boron concentrations reported in the open literature. The quasi-steady state power profiles calculated by PHISICS for the equilibrium cycle are stored in the HDF5 database for subsequent fuel performance and LB-LOCA analyses.

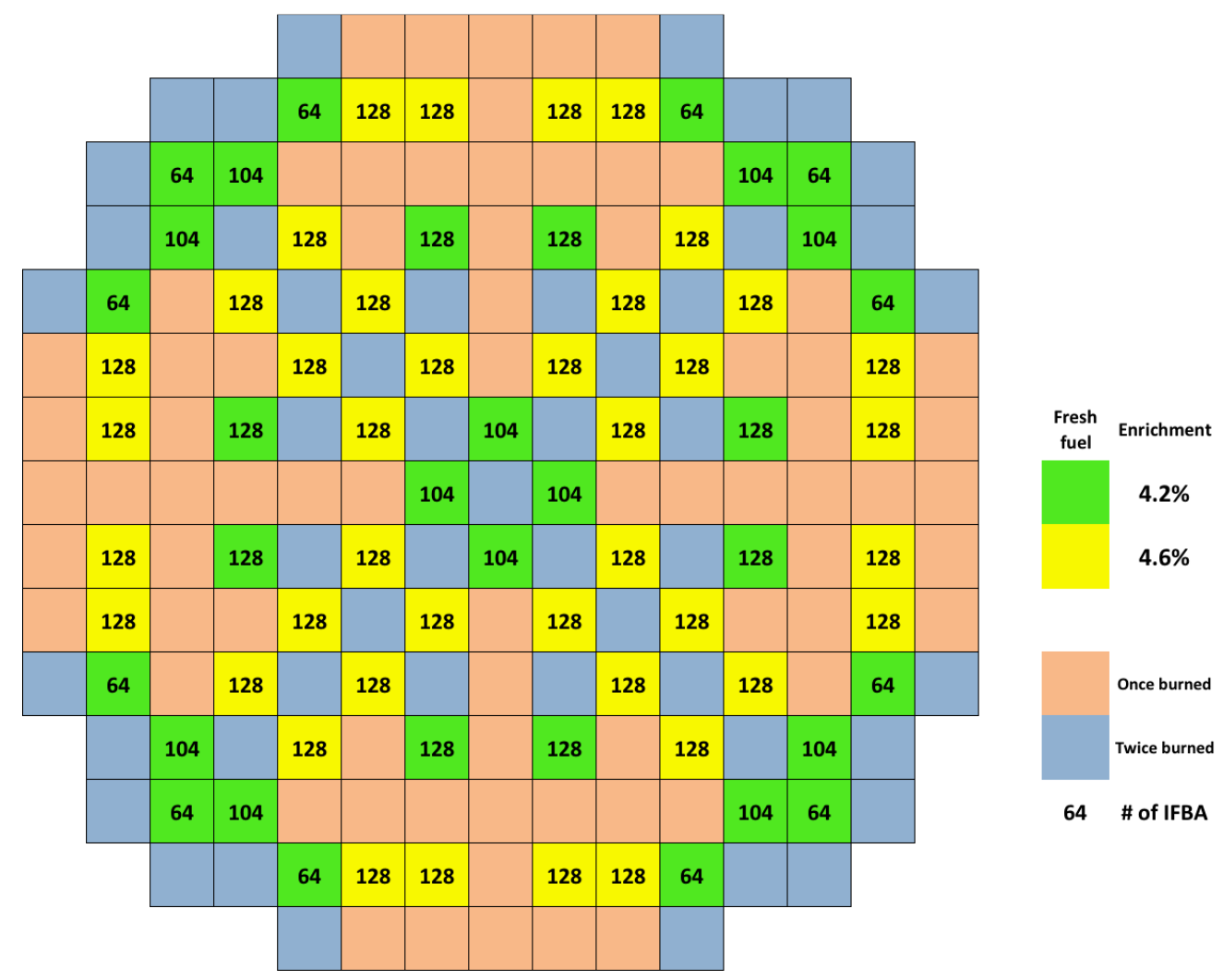

Figure 5. Equilibrium Cycle Reload Pattern, Fresh Fuel Enrichment and Number of Burnable Absorber (BA) Pins in the Fresh Fuel Assemblies.

\subsubsection{Fuel Performance}

Fuels performance calculations are performed for a representation of the hot rod and average rod (see section 3.3) for each fuel assembly. Each case is modeled with a single channel enthalpy rise model. Enrichments were inputted according to assembly locations (see Figure 5). The supplied power histories 
of each rod include the effects of core shuffling (see section 3.2). The code constant parameters of FRAPCON are given in Table III.

Table III. FRAPCON Code Parameters

\begin{tabular}{|l|c|}
\hline Parameter & Value \\
\hline Fuel Height & $4.2672 \mathrm{~m}(14 \mathrm{ft})$. \\
\hline Pitch & $0.195 \mathrm{~cm}(0.496 \mathrm{in})$. \\
\hline Plenum Height & $0.1778 \mathrm{~m}(7 \mathrm{in})$. \\
\hline Pellet Material & Uranium Dioxide \\
\hline Plenum Fill Gas & Helium \\
\hline Cladding Material Number & 6 \\
\hline Pellet Height & $9.8299 \mathrm{~mm}(0.387 \mathrm{in})$. \\
\hline Pellet Dish Height & $0.3353 \mathrm{~mm}(0.0132 \mathrm{in})$. \\
\hline Limit On Swelling Fraction & 0.05 \\
\hline Increase In Pellet Density & $150 \mathrm{~kg} / \mathrm{m}^{3}$ \\
\hline
\end{tabular}

\subsubsection{System Analysis}

The RELAP5-3D input deck describes a typical four-loop Pressurized Water Reactor (PWR). The reactor system is simulated using one-dimensional components and includes all the main reactor features of importance when simulating LOCA scenarios. This includes a detailed representation of the primary system (reactor vessel and internals, four independent loops with cold and hot legs, primary coolant pumps, and steam generators), pressurizer, and Emergency Core Cooling Systems. The reactor core is simulated with six vertical pipe components (radially connected through cross-junctions) and six axial nodes. Each assembly is represented as two heat structures (one for the hot pin and one for the remaining 263 pins). Each heat structure is comprised of six axial elements in order to partially capture the variations within axial power regions for each assembly. Each of these heat structures is connected to the appropriate hydrodynamic pipe component.

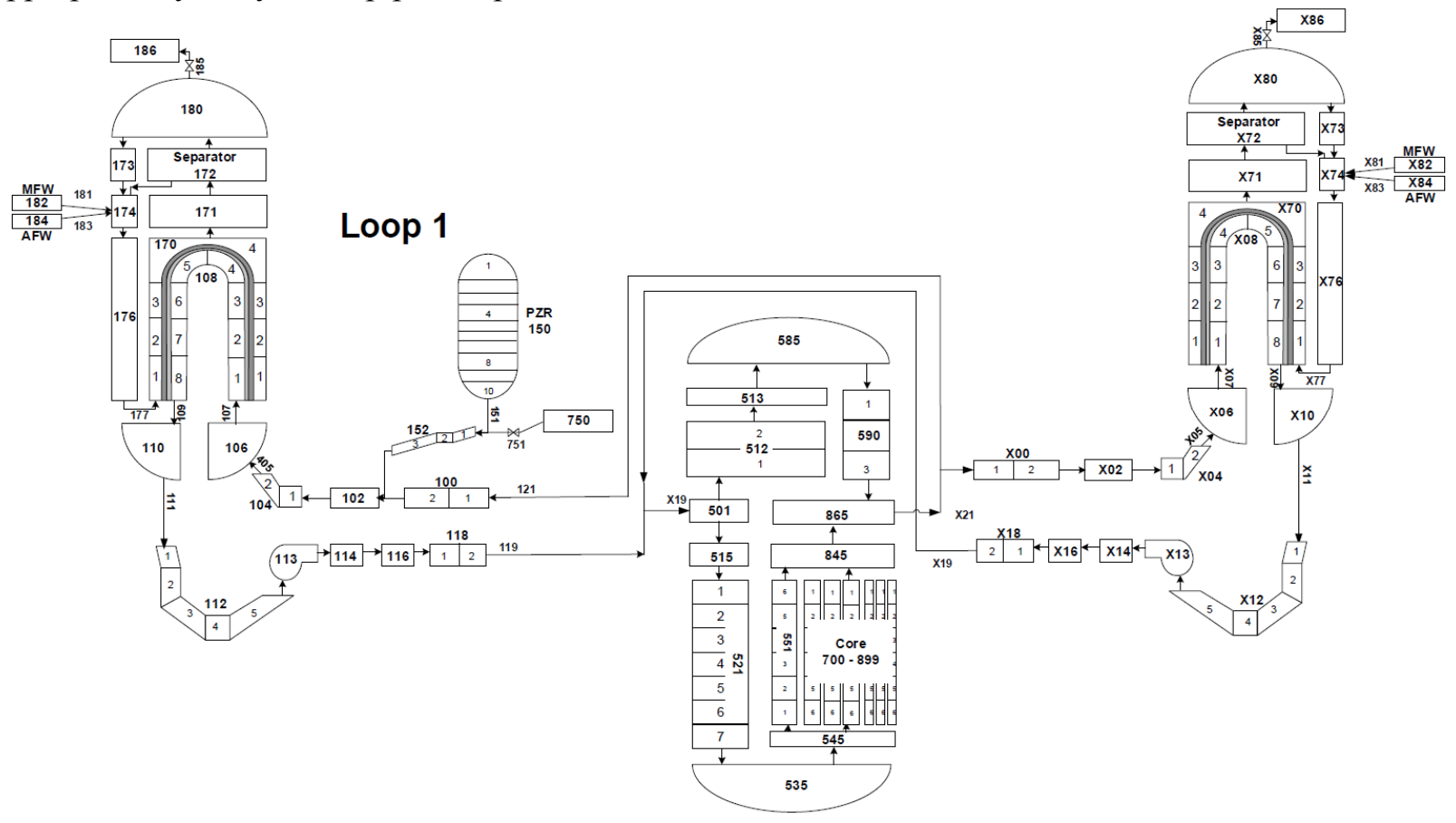

Figure 6: RELAP5-3D PWR Nodalization Diagram. 
The secondary loop includes the secondary side of the four steam generators up to the main steam isolation valves. The model is equipped with control logic to simulated automatic signals, and manual operating procedures adopted during LOCA. A simplified representation of the RELAP5-3D model of the reactor system is shown in Figure 6. The parameters within the RELAP5-3D input deck are vast and are not included here for the sake of brevity.

\subsection{Figures of Merit}

The peak cladding temperatures (PCT) is of critical importance in evaluating plant safety under LOCA conditions. PCT is the highest cladding temperature encountered during a LB-LOCA. Excessive PCT leads to cladding rupture as well as excessive cladding oxidation.

Evaluation of equivalent cladding reacted (ECR) is also essential. ECR is the percentage of the cladding which has been oxidized. Cladding oxidation is an exothermic reaction which increases in rate at higher coolant temperatures. Thus as more cladding is oxidized, the coolant temperature rises further, causing greater oxidation. This runaway reaction has the potential to create vast quantities of hydrogen within the reactor core, leading to a potentially combustible scenario.

In order to evaluate PCT and ECR with respect to their cladding hydrogen content based limits (see Figure 1), it is proposed that the figures of merit (FOM) be the ratios of PCT and ECR to their respective limits. The peak cladding temperature ratio (PCTR) and equivalent cladding reacted ratio (ECRR) are expressed in Eq.9 and Eq. 10 respectively,

$$
\begin{aligned}
& \text { PCTR }=\frac{P C T}{P C T_{\text {Limit }}\left(H_{2} \text { Conc. }\right)} \\
& E C R R=\frac{E C R}{E C R_{\text {Limit }}\left(H_{2} \text { Conc. }\right)}
\end{aligned}
$$

The functions of the limits of PCT and ECR are shown in Figure 1. The PCT is a simple step function of hydrogen concentration while the ECR limit is a pricewise continuous function whose value may decrease by an order of magnitude when comparing fresh fuel to highly irradiated fuel.

If we define $P C T R_{\max }$ and $E C R R_{\max }$ as the maximum values of PCTR and ECRR within a core at a given state, then the acceptance criteria for the safety metrics are the following:

and

$$
\text { 1) } P C T R_{\max }<1
$$

$$
\text { 2) } E C R R_{\max }<1
$$

Using the above criteria, the limiting fuel rods can be identified as the fuel rods with PCTR $R_{\max }$ or the $E C R R_{\max }$. It is worth noting that the limiting rods frequently change location within the perturbed samples.

The nature of ECRR in particular prevents a reliable method for predicting the assemblies of greatest concern a priori. This is due to high cladding hydrogen content being correlated with high burnup and 
high ECR corresponding to large local linear heat rates. Since higher burnup fuel has lower neutron cross sections and thus lower linear heat rates, there is no reasonable method to determine the ECRR limiting assembly without modeling each assembly in both FRAPOCN and RELAP5-3D.

\subsection{Uncertain Parameters and Random Sampling}

The uncertainty ranges and distributions of relevant parameters were generated from past UQ/SA work on fuel performance (Ikonen, 2016), coupled thermal hydraulics and neutronics (Brown \& Zhang, 2016), and system analysis (Zhang et al., 2017). It should be noted that many of the ranges of the perturbed inputs exclusive to RELAP5-3D were selected based off of common practices for expected uncertainties within thermal hydraulics (i.e. $30 \%$ uncertainty in heat transfer coefficients).

Table IV. List of Common Uncertain Parameters with Corresponding Uncertainty Ranges

\begin{tabular}{|c|c|c|c|c|c|}
\hline Parameter & Nominal & Range (+/-) & Distribution & FRAPCON & RELAP5-3D \\
\hline Fuel Radius & $0.40956 \mathrm{~cm}$ & $0.001 \mathrm{~cm}$ & Normal & $\mathrm{X}$ & $\mathrm{X}$ \\
\hline Clad Outer Radius & $0.47498 \mathrm{~cm}$ & $0.002 \mathrm{~cm}$ & Normal & $\mathrm{X}$ & $\mathrm{X}$ \\
\hline Clad Thickness & $0.05715 \mathrm{~cm}$ & $0.002 \mathrm{~cm}$ & Normal & $\mathrm{X}$ & $\mathrm{X}$ \\
\hline Plenum Fill Gas Pressure & $3.0 \mathrm{MPa}$ & $0.08 \mathrm{MPa}$ & Normal & $\mathrm{X}$ & $*$ \\
\hline Percent Theoretical Density & $94.5 \%$ & $1.6 \%$ & Normal & $\mathrm{X}$ & $\mathrm{X}$ \\
\hline Fuel Thermal Conductivity & - & $10 \%$ & Normal & $\mathrm{X}$ & $\mathrm{X}$ \\
\hline Core Power & $3.85 \mathrm{GW}$ & $2 \%$ & Normal & $\mathrm{X}$ & $\mathrm{X}$ \\
\hline Direct Moderator Heating & 0.02 & $10 \%$ & Normal & $\mathrm{X}$ & $*$ \\
\hline Decay Heat Multiplier & 1 & 0.06 & Uniform & & $\mathrm{X}$ \\
\hline Accumulator Pressure & $606 \mathrm{psi}$ & $10 \%$ & Normal & & $\mathrm{X}$ \\
\hline $\begin{array}{l}\text { Accumulator Liquid } \\
\text { Temperature }\end{array}$ & $\begin{array}{l}52.222^{\circ} \mathrm{C} \\
\left(126^{\circ} \mathrm{F}\right)\end{array}$ & $\begin{array}{c}13.889^{\circ} \mathrm{C} \\
\left(25^{\circ} \mathrm{F}\right)\end{array}$ & Uniform & & $\mathrm{X}$ \\
\hline $\begin{array}{l}\text { Accumulator Liquid } \\
\text { Volume }\end{array}$ & $\begin{array}{l}35.397 \mathrm{~m}^{3} \\
\left(1250 \mathrm{ft}^{3}\right)\end{array}$ & $\begin{array}{l}0.227 \mathrm{~m}^{3} \\
\left(8 \mathrm{ft}^{3}\right)\end{array}$ & Uniform & & $\mathrm{X}$ \\
\hline $\begin{array}{l}\text { Sub-Cooled Counter Flow } \\
\text { Multiplier (Pump Side) }\end{array}$ & 1 & 0.2 & Uniform & & $\mathrm{X}$ \\
\hline $\begin{array}{l}\text { Two-Phase Counter Flow } \\
\text { Multiplier (Pump Side) }\end{array}$ & 1 & 0.2 & Uniform & & $\mathrm{X}$ \\
\hline $\begin{array}{l}\text { Super-Heated Counter Flow } \\
\text { Multiplier (Pump Side) }\end{array}$ & 1 & 0.2 & Uniform & & $\mathrm{X}$ \\
\hline $\begin{array}{l}\text { Sub-Cooled Counter Flow } \\
\text { Multiplier (Vessel Side) }\end{array}$ & 1 & 0.2 & Uniform & & $\mathrm{X}$ \\
\hline $\begin{array}{l}\text { Two-Phase Counter Flow } \\
\text { Multiplier (Vessel Side) }\end{array}$ & 1 & 0.2 & Uniform & & $\mathrm{X}$ \\
\hline $\begin{array}{l}\text { Two-Phase Counter Flow } \\
\text { Multiplier (Vessel Side) }\end{array}$ & 1 & 0.2 & Uniform & & $\mathrm{X}$ \\
\hline $\begin{array}{l}\text { Turbulence Heat Transfer } \\
\text { Multiplier }\end{array}$ & 1 & 0.3 & Uniform & & $\mathrm{X}$ \\
\hline $\begin{array}{l}\text { Nucleate Boiling Heat } \\
\text { Transfer Multiplier }\end{array}$ & 1 & 0.3 & Uniform & & $\mathrm{X}$ \\
\hline $\begin{array}{l}\text { Critical Heat Flux } \\
\text { Multiplier }\end{array}$ & 1 & 0.3 & Uniform & & $\mathrm{X}$ \\
\hline $\begin{array}{l}\text { Transition Boiling Heat } \\
\text { Transfer Multiplier }\end{array}$ & 1 & 0.3 & Uniform & & $\mathrm{X}$ \\
\hline $\begin{array}{l}\text { Film Boiling Heat Transfer } \\
\text { Multiplier }\end{array}$ & 1 & 0.3 & Uniform & & $\mathrm{X}$ \\
\hline
\end{tabular}




\begin{tabular}{|l|c|c|c|c|c|}
\hline $\begin{array}{l}\text { Condensation Heat Transfer } \\
\text { Multiplier }\end{array}$ & 1 & 0.3 & Uniform & & $\mathrm{X}$ \\
\hline $\begin{array}{l}\text { Natural Convection Heat } \\
\text { Transfer Multiplier }\end{array}$ & 1 & 0.3 & Uniform & & $\mathrm{X}$ \\
\hline $\begin{array}{l}\text { Laminar Heat Transfer } \\
\text { Multiplier }\end{array}$ & 1 & 0.3 & Uniform & & $\mathrm{X}$ \\
\hline Fuel Enrichment & $2.6 / 4.2 / 4.6$ & $0.003 \%$ & Normal & $\mathrm{X}$ & \\
\hline Fuel Roughness & $2.0 \mu \mathrm{m}$ & $0.33333 \mu \mathrm{m}$ & Normal & $\mathrm{X}$ & \\
\hline Clad Roughness & $1.0 \mu \mathrm{m}$ & $0.2 \mu \mathrm{m}$ & Normal & $\mathrm{X}$ & \\
\hline Fuel Thermal Expansion & - & $15 \%$ & Normal & $\mathrm{X}$ & \\
\hline $\begin{array}{l}\text { Fission Gas Release } \\
\text { Biasing }\end{array}$ & - & $+200 \% /-67 \%$ & Normal & $\mathrm{X}$ & \\
\hline Fuel Swelling & - & $20 \%$ & Normal & $\mathrm{X}$ & \\
\hline Clad Creep & - & $30 \%$ & Normal & $\mathrm{X}$ & \\
\hline Clad Axial Growth & - & $50 \%$ & Normal & $\mathrm{X}$ & \\
\hline Clad Oxidation & - & $80 \mathrm{ppm}$ & Normal & $\mathrm{X}$ & \\
\hline CladH2Pickup & $\begin{array}{c}15.686 \mathrm{MPa} \\
(2275 \mathrm{psi})\end{array}$ & $2 \%$ & Normal & $\mathrm{X}$ & \\
\hline Outlet Pressure & $\begin{array}{c}3533.596 \\
\mathrm{~kg} / \mathrm{s}-\mathrm{m}^{2} \\
(2605453 \\
\mathrm{bm} / \mathrm{hr}^{2} \mathrm{ft}^{2}\end{array}$ & $2 \%$ & Normal & $\mathrm{X}$ & \\
\hline Inlet Mass Flux & & & & \\
\hline
\end{tabular}

* Indicates inputs supplied to code are directly affected by perturbed value of row. Normal indicates truncated normal distribution of two standard deviations.

The * in Table IV indicates that the perturbed input of that row strongly influences the program of the corresponding column despite it not being a direct input. For instance, the initial plenum fill gas pressure of FRAPCON is not inputted to RELAP5-3D. However the plenum gas pressure at various states, which are highly dependent on the initial pressure, are included in RELAP5-3D input decks. The direct moderator heating fraction is also not directly supplied, however LOTUS scripts use the fraction in determining the portion of the core power to be placed in direct moderator heating within RELAP5-3D. Lastly in the nominal value column, a '-'entry indicates that a continually varying value within the code is biased by a specified amount, thus a nominal value does not exist.

\subsection{Wilks' UQ Method}

Wilks' method was introduced in 1941 by its namesake (Wilks, 1941). Wilks' method entails finding tolerance limits for a population based off of a limited sample size. The method may be used for any output probability distribution function so long as it is continuous. While this is not technically true of floating point numbers, it is nevertheless a very fair assumption to treat code outputs as continuous variables.

To calculate a confidence interval, it is convenient to first state the probability $\beta$ that at least one value of a sample of size $N$ lies outside portion $\gamma$ of the population, as shown in Eq. 11,

$$
\beta=1-\gamma^{N}
$$

In order to find a one sided $95 / 95$ confidence value, the question can be asked, given that $\gamma=0.95$, what is 
the minimal $N$ for which $\beta$ is greater than or equal to 0.95 ? By setting $N$ to 59 , there is 95.15 probability that at least one value is greater than the $95^{\text {th }}$ percentile of the population. Thus by performing any set of perturbed calculations 59 times, the highest obtained value serves as a conservative bound for a 95/95 confidence interval.

This process has been expanded to determine the confidence intervals based upon upper and lower bounds for arbitrary ranks (Guba et al., 2003). The probability that a lower bound of ranks $r$ and upper bound of rank $s$ bound portion $\gamma$ is given by Eq. 12,

$$
\beta=\sum_{j=0}^{s-r-1}\left(\begin{array}{l}
N \\
j
\end{array}\right) \gamma^{j}(1-\gamma)^{N-j}
$$

Wilk's method has been further expanded by Guba et al. for multiple outputs (Guba et al., 2003). This is not to be misinterpreted that Eq. 11 and 12 are inadequate for simulations producing multiple outputs. Rather, if a decision maker desires to construct multidimensional bounds (i.e. rectangular bounds for two outputs), then the required sample sizes and ranks must be modified. For a problem of order $p$, the probability that ranks $r=0$ and $s=N-p+1$ bound portion $\gamma$ of the population is given by Eq. 13,

$$
\beta=\sum_{j=0}^{j=N-p}\left(\begin{array}{l}
N \\
j
\end{array}\right) \gamma^{j}(1-\gamma)^{N-j}
$$

For evaluation of PCTR and ECRR ( $p=2)$, Eq. 13 indicates that if a $\beta$ of at least 0.95 is desired with no lower bounds $(r=0)$, and the highest and second highest values set as upper bounds for the first and second output respectively $(s=N-p+1)$, then a sample size of at least 93 is required. In order to ensure outputs are treated equally, it has become a common practice in the nuclear safety community to take the highest rank of all outputs as bounds (Frepoli, 2008). While this is more conservative, it still qualifies as bounding $95 \%$ or more of the population with at least $95 \%$ confidence.

\section{RESULTS}

LB-LOCA scenario simulations are run at a variety of states throughout the equilibrium fuel cycle (BOC, 100 days, 200 days, 300 days, 400 days, 500 days, EOC). The results are divided into two sections. The first containing the nominal and one sided 95/95 confidence values determined via the Wilks' method (section 5.1). The second section includes the ECR, PCT, hydrogen content, and burnup information for the limiting cases of the Wilks' sample (section 5.2).

\subsection{UQ Results}

The nominal and one sided 95/95 confidence values for $P C T R_{\max }$ are given in Table V. 
Table V: Statistical PCTR Information from Wilks' Study

\begin{tabular}{|c|c|c|}
\hline Time of LB-LOCA & Nominal $\boldsymbol{P C T} \boldsymbol{R}_{\max }$ & One Sided 95/95 PCT $\boldsymbol{R}_{\max }$ \\
\hline BOC & 0.5900 & 0.7135 \\
\hline 100 Day & 0.5912 & 0.6377 \\
\hline 200 Day & 0.6064 & 0.6701 \\
\hline 300 Day & 0.6346 & 0.7209 \\
\hline 400 Day & 0.6458 & 0.8477 \\
\hline 500 Day & 0.6263 & 0.7048 \\
\hline EOC & 0.6484 & 0.7324 \\
\hline
\end{tabular}

The $P C T R_{\max }$ values within Table V show sporadic fluctuation between the times for LB-LOCA for both nominal values (less than $11.6 \%$ variation) and $95 / 95$ values (less than $12.9 \%$ variation). The changes in PCTR $R_{\max }$ from state to state stem from two factors. The first factor is the PCTR being a strong function of assembly power and axial peaking profiles. The second factor is the PCT limit changing from $1477.59 \mathrm{~K}$ to $1394.26 \mathrm{~K}$ when the cladding of higher burnup has hydrogen content in excess of 400 wppm (see Figure 1), resulting in a 6\% PCTR increase. Thus PCTR fluctuations do not follow a specific trend when comparing the time of LB-LOCA. The results for ECRR is given in Table VI.

Table VI: Statistical ECRR Information from Wilks' Study

\begin{tabular}{|c|c|c|}
\hline Time of LB-LOCA & Nominal $\boldsymbol{E C R R}_{\max }$ & One Sided 95/95 ECR $_{\text {max }}$ \\
\hline BOC & 0.0042 & 0.0339 \\
\hline 100 Day & 0.0032 & 0.0072 \\
\hline 200 Day & 0.0063 & 0.0262 \\
\hline 300 Day & 0.0149 & 0.0787 \\
\hline 400 Day & 0.0214 & 0.1281 \\
\hline 500 Day & 0.0261 & 0.1338 \\
\hline EOC & 0.0387 & 0.1350 \\
\hline
\end{tabular}

The $E C R R_{\max }$ values in general shows an increasing trend as the LB-LOCA occurs later in the fuel cycle. This behavior is attributable to the ECR limit being a strong function of hydrogen content (see Figure 1). At the EOC, the hydrogen content can be in excess of $650 \mathrm{wppm}$ (see Figure 14) causing the ECR limit to be as much of a factor of 5 less than the limit for fresh fuel.

Table V and VI highlight the benefits of the MP-BEPU methodology. The inclusion of the uncertainty in the calculation results in as much as a $31.2 \%$ increase in $P C T R_{\max }$ estimates and over an 8 fold increase in $E C R R_{\max }$ estimates. The drastic differences in $E C R R_{\max }$ are due to the limiting cases having far more cladding oxidation then the nominal cases. When oxide forms, heat is released causing coolant temperatures increases, which in turn causes more oxidation. This unstable relation causes ECRR to behave as a threshold variable, meaning a variable which changes drastically once a threshold is passed. This behavior in particular demonstrates the need for decision makers to be supplied with data obtained through MP-BEPU methodologies.

\subsection{Limiting Cases}

Figures 7 through 13 show the core maps of PCT and ECR for the limiting cases for an LB-LOCA occurring at seven separate states. The limiting case is defined as the instance of the perturbed sample from the Wilks' study which is of greatest concern from either a $P C T R_{\max }$ or $E C R R_{\max }$ perspective. As described in section 4.4, each limiting case will contain a 95/95 confidence value for the assembly of greatest concern. The specific limiting case for $P C T R_{\max }$ often differs from that of $E C R R_{\max }$. 
Furthermore, the limiting cases also vary from state to state. The data of Figures 7 through 13 originated from the hot pin heat structures of RELAP5-3D, with no data coming from the average pin fuel structures.
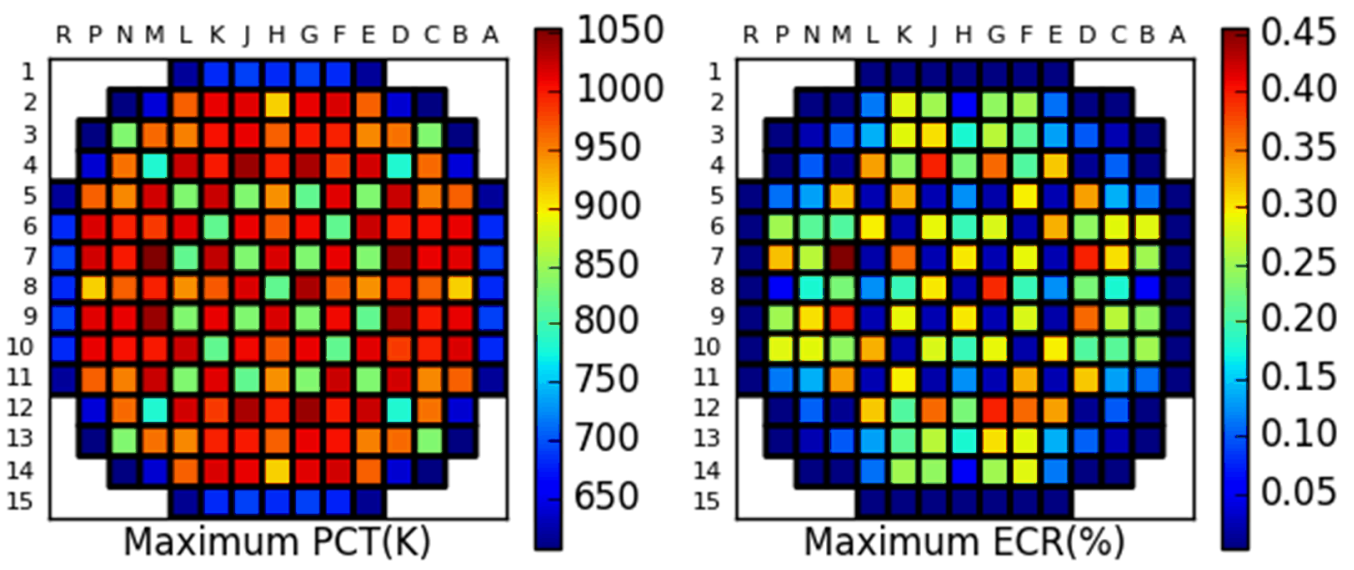

Figure 7: PCT and ECR Core Map for Limiting Case at BOC.

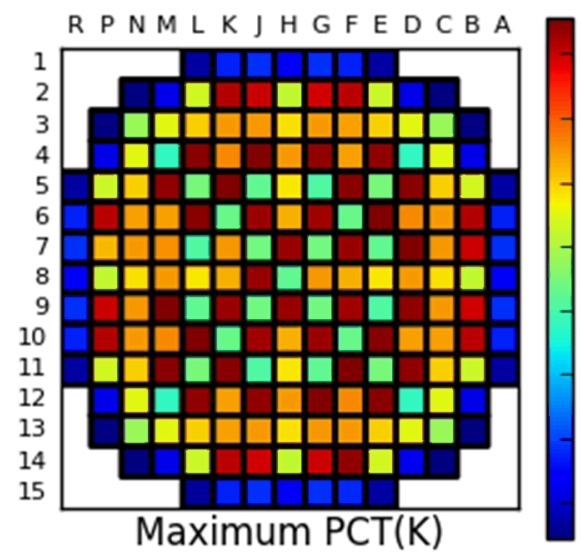

920
880
840
800
760
720
680
640

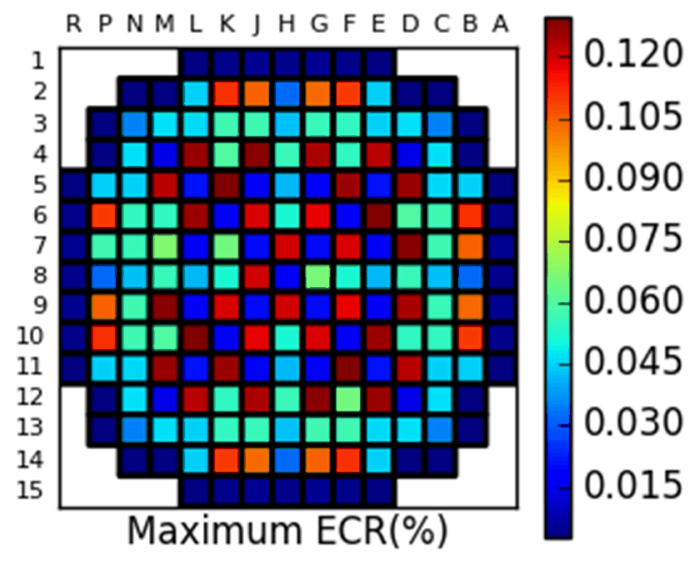

Figure 8: PCT and ECR Core Map for Limiting Case at 100 Days.
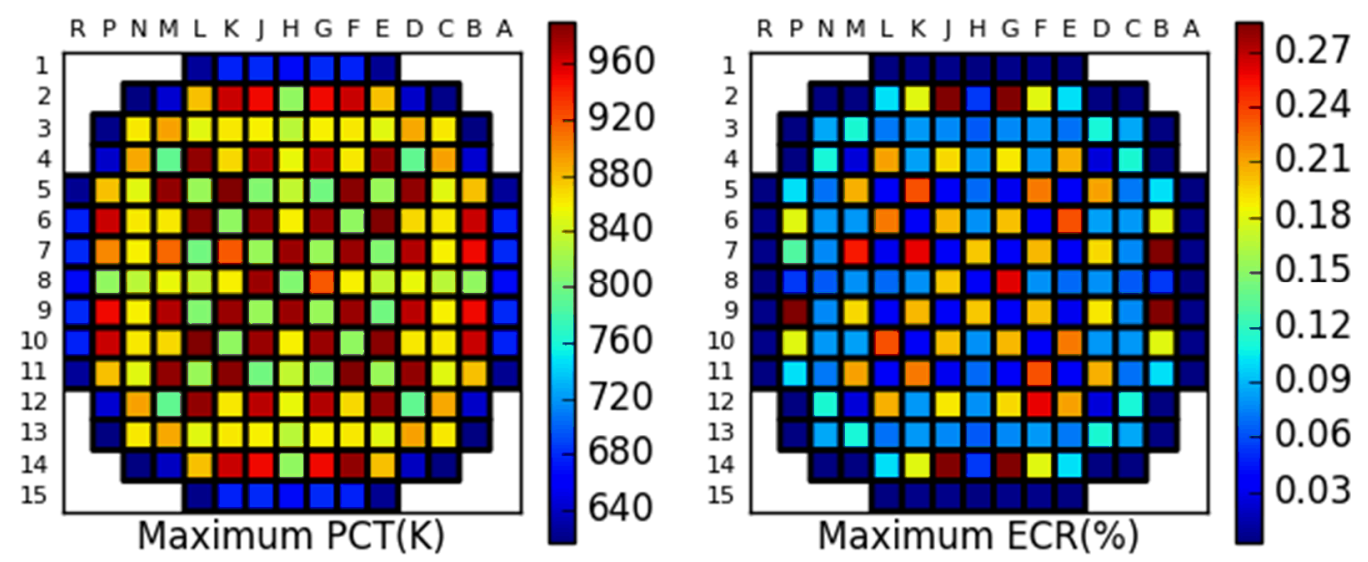

Figure 9: PCT and ECR Core Map for Limiting Case at 200 Days. 

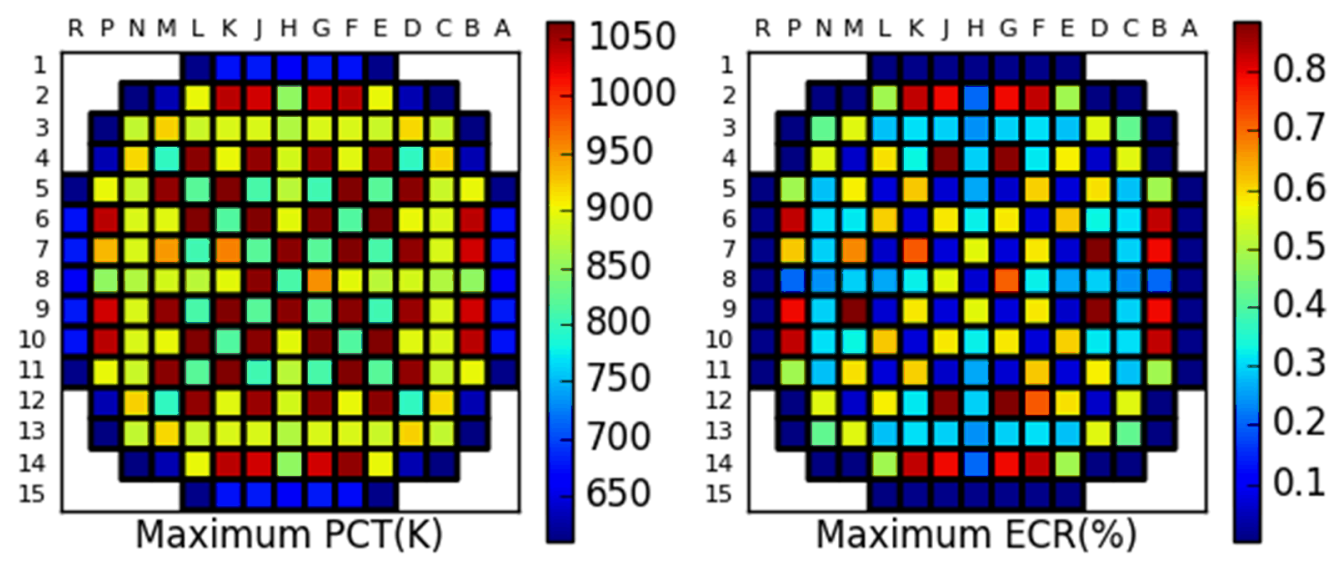

Figure 10: PCT and ECR Core Map for Limiting Case at 300 Days.
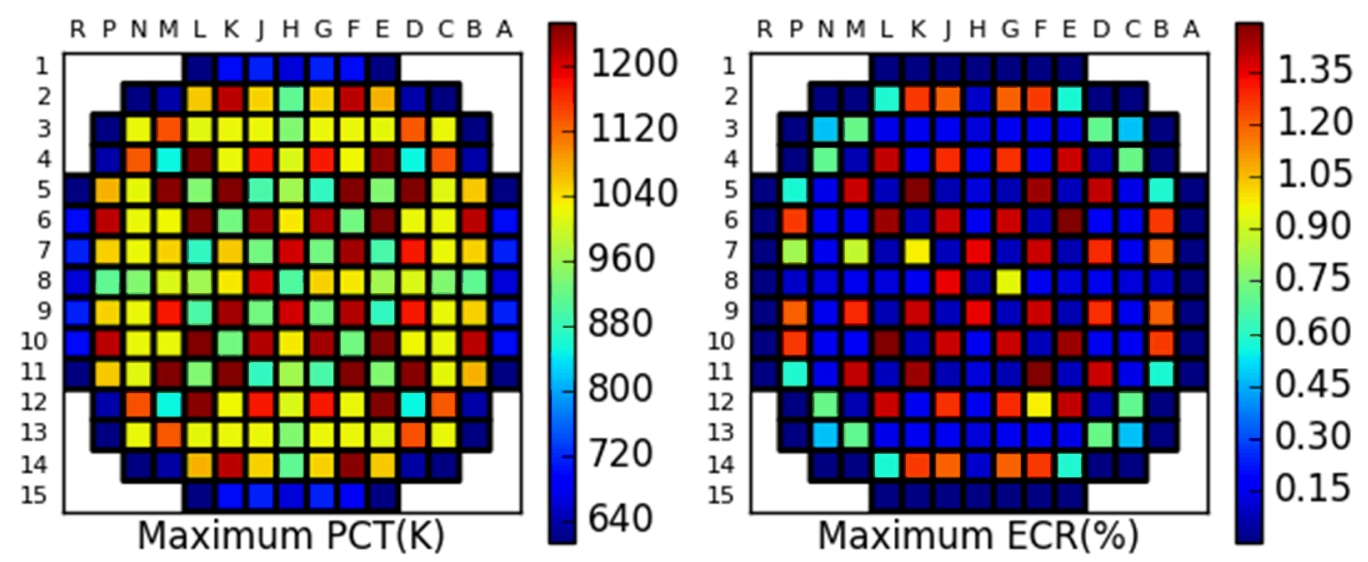

Figure 11: PCT and ECR Core Map for Limiting Case at 400 Days.
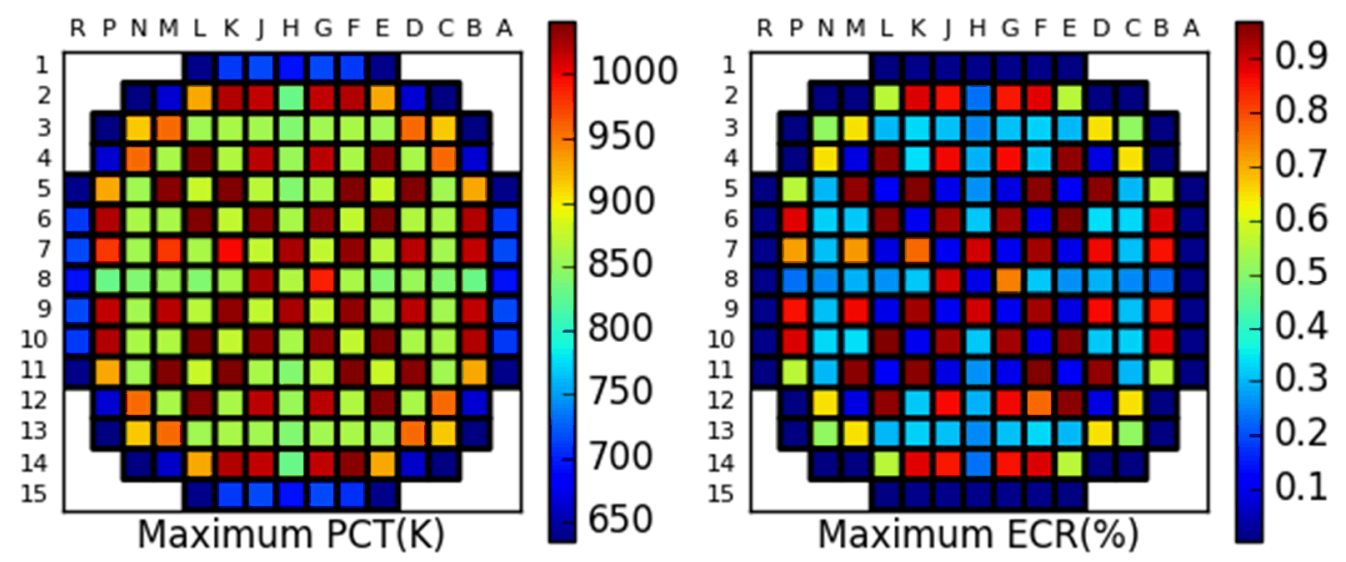

Figure 12: PCT and ECR Core Map for Limiting Case at 500 Days. 

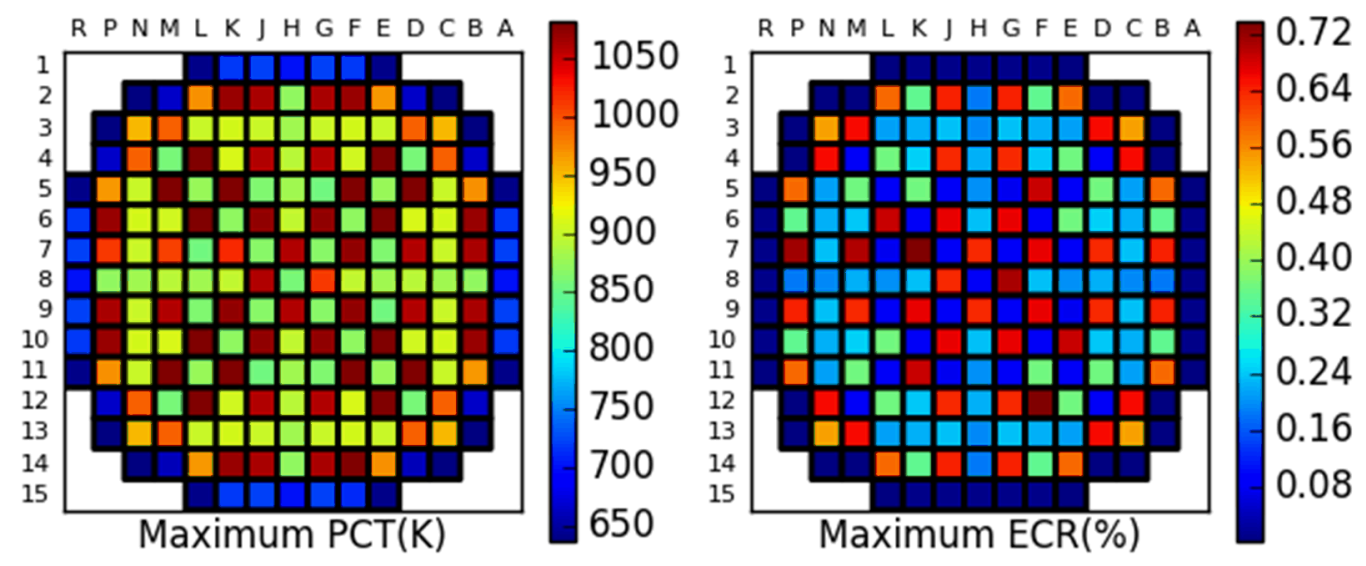

Figure 13: PCT and ECR Core Map for Limiting Case at EOC.

Not surprisingly, the highest PCT values always coincide with fresh assembly locations (compare reload pattern in Figure 5) due the increased neutron fission cross sections, and thus assembly power. It is for this same reason that the PCT values of fresh assemblies are often largest for higher enrichment fresh fuel (compare fresh fuel enrichments in Figure 5). The high PCT fresh assemblies vary from state to state, however the distribution is roughly symmetrical with high enrichment assemblies not in proximity to the core boundary being the most limiting.

The ECR values behave less predictably. While the limiting assemblies all contain fresh fuel, the specific location among fresh fuel assembly does not follow a specific trend. Furthermore, the ECR distributions are asymmetrical. This asymmetry can be traced back to minor difference (roughly $2 \%$ ) in the PHISICS generated power shapes for supposedly symmetric locations. As discussed in section 5.1, due to ECR being a threshold variable, minor differences may cause radically different results.

Figure 14 contains the PCT data for the assemblies in the limiting cases for a LB-LOCA occurring at the aforementioned states. The data includes PCT vs hydrogen content for each assembly in addition to the PCT limit as a function of hydrogen content. Figure 14 also contains a similar plot for PCT vs fuel burnup. As indicated by the legend, colors red, yellow, and green respond to fresh, once burned, and twice burned assemblies respectively. Figure 15 contains an analogous set of plots for ECR data. Note that the ECR limit as a function of cladding hydrogen content was not plotted due to all ECR values being far below said limit. As before, all data within Figures 14 and 15 was generated from the hot pin heat structures within RELAP5-3D. 


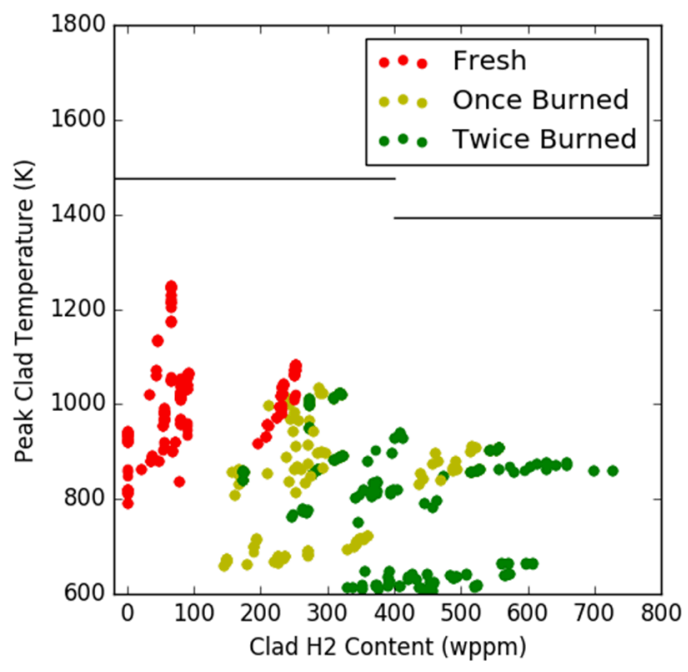

PCT vs Clad H2 Content

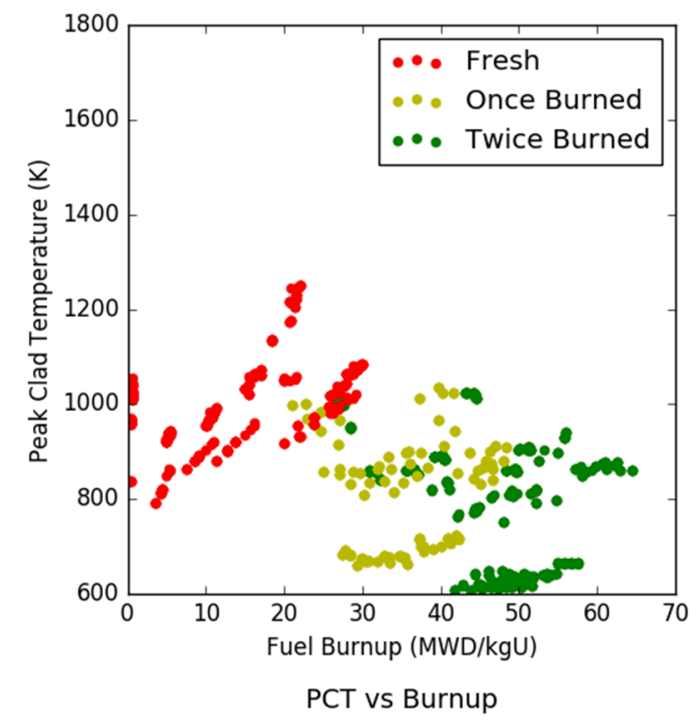

Figure 14: PCT and PCT Limit vs Cladding Hydrogen Content and PCT vs Fuel Burnup for the PCTR Limiting Cases at each State of Interest (BOC,100 days, 200 days, 300 days, 400 days, 500 days, EOC).

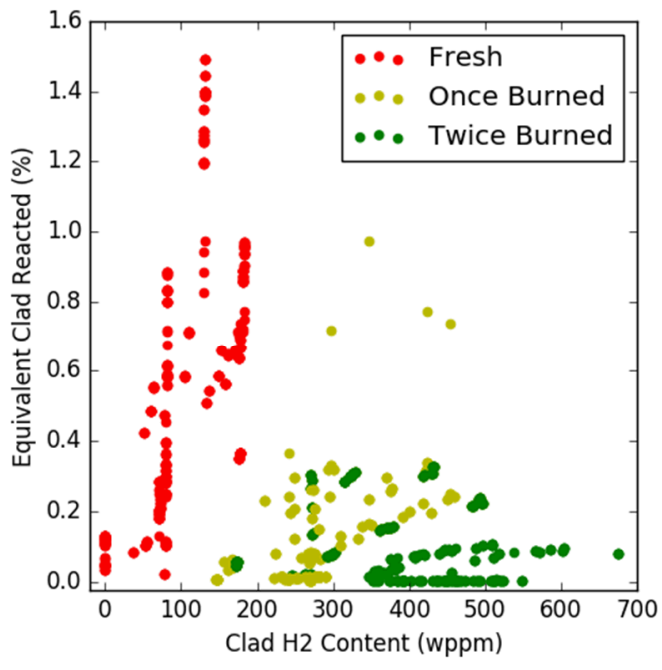

ECR vs Clad H2 Content

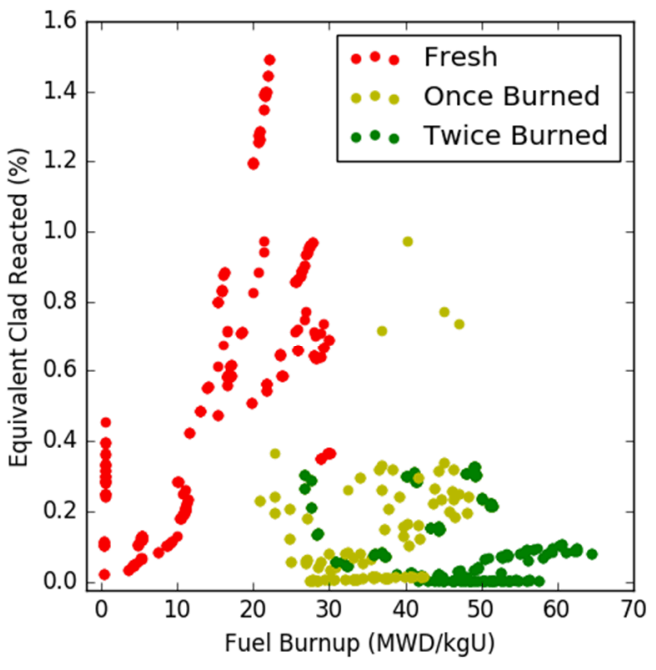

ECR vs Burnup

Figure 15: ECR vs Cladding Hydrogen Content and ECR vs Fuel Burnup for the ECRR Limiting Cases at each State of Interest (BOC,100 days, 200 days, 300 days, 400 days, 500 days, EOC).

Figure 14 indicates that the PCT fluctuations within assemblies is larger than the PCT limit reduction occurring at $400 \mathrm{ppm}$. As a result, from the PCTR perspective, the assemblies of greatest concerns are the fresh fuel assemblies with high assembly power. Figure 15 shows a number of outliers in the once burned fuel with values of roughly $1 / 2$ to $2 / 3$ the maximum ECR, but with reduced ECR limits which may be as low as a $1 / 3$ of the fresh fuel ECR limit. Therefore a small number of once burned assemblies are the most limiting in terms of $E C R R_{\max }$.

Figure 15 in particular establishes the benefits of using MP-BEPU methodology, specifically the multiphysics aspect. If the fuel performance and system analysis calculations were performed separately, 
then ECRR may have been evaluated with the limiting value of ECR from RELAP5-3D and the limiting value of cladding hydrogen content from FRAPCON. However, Figure 15 indicates that high ECR assemblies have low cladding hydrogen content, and assemblies with high cladding hydrogen content have low ECR. In reality, the true limiting assembly $\left(E C R R_{\max }\right)$ contains neither the core maximum of ECR nor hydrogen content. Thus MP-BEPU methodology helps to avoid a needlessly conservative estimate of $E C R R_{\max }$.

\section{CONCLUSIONS AND FUTURE WORK}

LOTUS utilizes HDF5 databases to create a flexible plug and play environment capable of UQ. LOTUS was used to integrate the core design code PHISCS, fuel performance code FRAPCON, and system analysis code RELAP5-3D. This integration provides MP-BEPU for system level plant transient analysis. LOTUS allows for the cladding hydrogen content based evaluation of PCT and ECR in accordance with the U.S. NRC's proposed rulemaking in 10 CFR 50.46c.

The Wilks's one sided 95/95 confidence values for the FOM were dramatically higher than their corresponding nominal values, thus demonstrating the necessity of following MP-BEPU methodology. Core maps of PCT and ECR for the limiting case for seven separate states were presented. Further visualization of the limiting cases included plots of PCT and ECR with respect to cladding hydrogen content and fuel burnup. Results reaffirmed the need to model all core assemblies with both fuel performance and system analysis codes in order to obtain the true limiting assembly for a given case.

Future work will include a Monte Carlo sampling of the integration of this work and subsequent Sensitivity Analysis (SA) with traditional regression based correlation coefficients as well as more sophisticated measures capable of detecting nonlinear relations. Future work will also include tight couplings of fuel performance and thermal hydraulic codes in the interests of improving simulations of transient scenarios. And lastly, neutronics codes capable of delivering sub pin power distributions (such as VERA-CS (https://www.casl.gov/, 2018)) will be integrated into the LOTUS framework.

\section{ACKNOWLEDGMENTS}

This work is supported by the U.S. Department of Energy, under DOE Idaho Operations Office Contract DE-AC07-05ID14517. Accordingly, the U.S. Government retains a nonexclusive, royalty-free license to publish or reproduce the published form of this contribution, or allow others to do so, for U.S. Government purposes. This work was also supported by consultations and contributions from Cliff Davis and Paul Bayless.

\section{REFERENCES}

1. Sloan B., McCorkle D. and Bryden K. "An Overview of Computational Environments for Engineering". Proceedings of 51st AIAA Aerospace Sciences Meeting including the New Horizons Forum and Aerospace Exposition, Dallas/Fort Worth Region. January 7-10, 2013.

2. Gaston D., Newman C., Hansen G. and Lebrun-Grandie D. (2009). "MOOSE: A parallel computational framework for coupled systems of nonlinear equations." Nuclear Engineering and Design 239(10): pp. 1768-1778.

3. https://www.casl.gov/, 2018.

4. Swiler L. P., Lefebvre R. A., Langley B. R. and Thompson A. B. (2017). "Integration of Dakota into the NEAMS Workbench", Sandia National Laboratories (SNL-NM), Albuquerque, NM (United States), SAND2017-7492.

5. https://www.hdfgroup.org/solutions/hdf5/, 2018. 
6. U.S. Nuclear Regulatory Commission (2014). "Establishing Analytical Limits for ZirconiumAlloy Cladding Material." Regulatory Guide 1.224, DG-1263.

7. The RELAP5-3D Code Development Team (2012). "RELAP5-3D Code Manual Volume I: Code Structure, System Models, and Solution Methods." Rev. 4, Idaho National Labs (INL), Idaho Falls, ID (United States), INEEL-EXT-98-00834.

8. http://frapcon.labworks.org/, 2018.

9. Weaver W. L., Tomlinson E. and Aumiller D. (2002). "A generic semi-implicit coupling methodology for use in RELAP5-3D." Nuclear Engineering and Design 211(1): pp. 13-26.

10. Marra Neto A., Silva A. T., Sabundjian G. and Conti T. N. "Link of FRAP-T, FRAPCON and RELAP-4 Codes for Fuel Rod Behaviour Analysis Under Transient and Accident Conditions in Light Water Reactors". Proceedings of $7^{\text {th }}$ National Meeting of Reactor Physics and Thermohydraulics, Brazil. 20, April 26-28, 1989.

11. Porter I., Knight T. W. and Raynaud P. (2015). "Potential Impacts of Modeling Full Reactor Cores Using Combined Fuel Performance and Thermal Hydraulics Codes." Nuclear Technology 190(2): pp. 174-182.

12. Magedanz J., Avramova M., Perin Y. and Velkov A. (2015). "High-fidelity multi-physics system TORT-TD/CTF/FRAPTRAN for light water reactor analysis." Annals of Nuclear Energy 84: pp. 234-243.

13. Yilmaz M. O., Avramova M. N. and Andersen J. G. M. (2017). "Multi-physics code system with improved feedback modeling." Progress in Nuclear Energy 98: pp. 94-108.

14. Folsom C. P., Jensen C. B., Williamson R. L., Woolstenhulme N. E., Ban H. and Wachs D. M. (2016). "BISON Modeling of Reactivity-Initiated Accident Experiments in a Static Environment", Idaho National Lab. (INL), Idaho Falls, ID (United States), INL/CON-16-37614.

15. Epiney A. S., Parisi C., Alfonsi A., Zhang H. and Szilard R. "RISMC Industry Application\# 1 (ECCS/LOCA) Core Characterization Automation: Reference PWR designs for IA\#1." Transactions of the American Nuclear Society, San Francisco, California (United States) 116, June 11-15, 2017.

16. Strydom G., Epiney A. S., Alfonsi A. and Rabiti C. (2017). "Comparison of the PHISICS/RELAP5-3D Ring and Block Model Results for Phase I of the OECD/NEA MHTGR350 Benchmark." Nuclear Technology 193(1): pp. 15-35.

17. Judd J., Grandi G. and Redwine J. "A best-estimate coupled code for reactor safety analyses using SIMULATE-3K and RELAP5-3D". Proceedings of Advances in Nuclear Fuel Management IV, Hilton Head Island, SC, USA. April 12-15, 2009.

18. Bratton R. N., Jessee M. A. and Wieselquist W. A. (2015). "Rod internal pressure quantification and distribution analysis using FRAPCON", Oak Ridge National Laboratory (ORNL), Oak Ridge, TN (United States), ORNL/TM-2015/557.

19. Deng Y., Shirvan K., Wu Y. and Su G. (2018). "Probabilistic view of SiC/SiC composite cladding failure based on full core thermo-mechanical response." Journal of Nuclear Materials 507: pp. 24-37.

20. Hales J., Tonks M., Gleicher F., Spencer B., Novascone S., Williamson R., Pastore G. and Perez D. (2015). "Advanced multiphysics coupling for LWR fuel performance analysis." Annals of Nuclear Energy 84: pp. 98-110.

21. Wu X., Kozlowski T. and Hales J. D. (2015). "Neutronics and fuel performance evaluation of accident tolerant FeCrAl cladding under normal operation conditions." Annals of Nuclear Energy 85: pp. 763-775. 
22. Gleicher F. N., Ortensi J., Spencer B. W., Wang Y., Novascone S. R., Hales J. D., Gaston D., Williamson R. L. and Martineau R. C. "The Coupling of the Neutron Transport Application RATTLESNAKE to the nuclear Fuels Performance Application BISON under the MOOSE Framework". Proceedings of PHYSOR, Kyoto (Japan). Sept 28-Oct 3, 2014, INL/CON-1431079.

23. Rabiti C., Alfonsi A. and Epiney A. (2016). "New Simulation Schemes and Capabilities for the PHISICS/RELAP5-3D Coupled Suite." Nuclear Science and Engineering 182(1): pp. 104-118.

24. Wang Y., Rabiti C. and Palmiotti G. "Krylov Solvers Preconditioned with the Low-Order RedBlack Algorithm for the PN Hybrid FEM for the INSTANT Code". Proceedings of International Conference on Mathematics and Computational Methods Applied to Nuclear Science and Engineering, Rio de Janeiro, Brazil. May 8-12, 2011.

25. Epiney A., Rabiti C., Alfonsi A., Wang Y., Cogliati J. and Strydom G. "PHISICS multi-group transport neutronic capabilities for RELAP5". Proceedings of ICAPP, Chicago (United States). 12, June 24-28, 2012.

26. Alfonsi A., Rabiti C., Epiney A. S., Wang Y. and Cogliati J. "PHISICS toolkit: Multi-Reactor Transmutation Analysis Utility-MRTAU". Proceedings of PHYSOR 2012, Knoxville, Tennessee, USA, Idaho National Laboratory (INL). April 15-20, 2012, INL/CON-11-23985.

27. Wemple C., Gheorghiu H., Stamm'ler R. and Villarino E. "The HELIOS-2 lattice physics code". Proceedings of 18th AER Symposium on VVER Reactor Physics and Reactor Safety, Eger (Hungary). October 6-10, 2008.

28. Ikonen T. (2016). "Comparison of global sensitivity analysis methods-application to fuel behavior modeling." Nuclear Engineering and Design 297: pp. 72-80.

29. Brown C. and Zhang H. (2016). "Uncertainty quantification and sensitivity analysis with CASL Core Simulator VERA-CS." Annals of Nuclear Energy 95: pp. 188-201.

30. Zhang H., Szilard R., Epiney A., Parisi C., Vaghetto R., Vanni A. and Neptune K. (2017). "Industry Application ECCS / LOCA Integrated Cladding/Emergency Core Cooling System Performance: Demonstration of LOTUS-Baseline Coupled Analysis of the South Texas Plant Model", Idaho National Lab. (INL), Idaho Falls, ID (United States), INL/EXT-17-42461.

31. Wilks S. S. (1941). "Determination of sample sizes for setting tolerance limits." The Annals of Mathematical Statistics 12(1): pp. 91-96.

32. Guba A., Makai M. and Pál L. (2003). "Statistical aspects of best estimate method-I." Reliability engineering \& system safety 80(3): pp. 217-232.

33. Frepoli C. (2008). "An overview of Westinghouse realistic large break LOCA evaluation model." Science and Technology of Nuclear Installations. 